\title{
Chapter
}

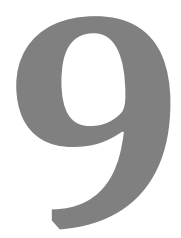

\section{THE ONLY WAY TO FILL THE GAP: COMBINATIONS OF REPURPOSED DRUGS AGAINST ANTIBIOTIC RESISTANCE AND LETHAL SEPSIS}

\section{David Brown}

Alchemy Biomedical Consulting, St Johns Innovation Centre, Cowley Road, Cambridge, United Kingdom, CB4 0WS 


\section{Contents}

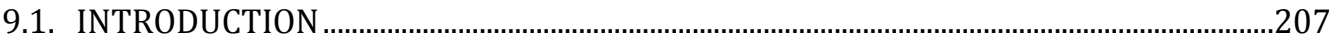

9.2. WHY DEATHS WILL INCREASE BEFORE THE ANTIBIOTIC GAP IS FILLED ..................209

9.2.1. Current actions are too little and too late .................................................................209

9.2.2 Limitations of the current antibiotic pipeline .....................................................211

9.3. REPURPOSING ANTIBIOTICS: ANTIBIOTIC COMBINATIONS TO BREAK

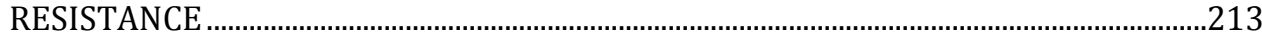

9.3.1. Beta-lactams combined with one or two beta-lactamase inhibitors..................213

9.3.2. Antibiotics combined with a second or third antibiotic .........................................214

9.3.3. Combinations of bacteriostatic antibiotics to side-step MBLs and CREs and reduce organ damage in septic shock

9.4. REPURPOSING NON-ANTIBIOTIC DRUGS TO PREVENT ORGAN DAMAGE AND DEATH FROM SEPSIS

9.4.1. Vitamin C, thiamine and hydrocortisone triple therapy........................................219

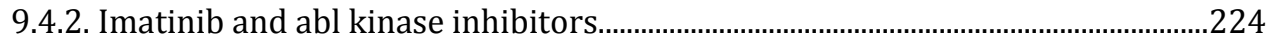

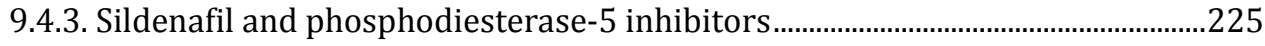

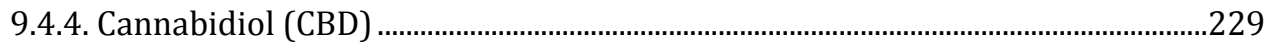

9.4.5. Immune regulation by (some) antibiotics ...............................................................232

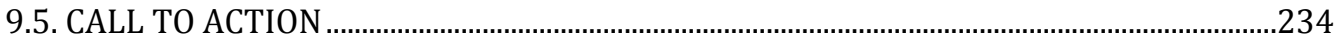

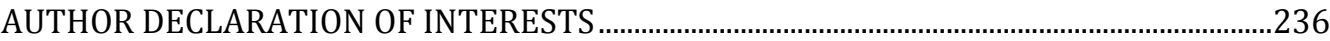

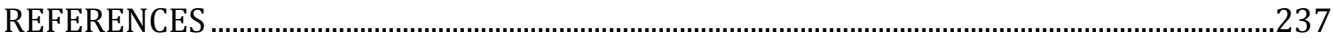




\subsection{INTRODUCTION}

Discovery of new antibiotics that are effective against Gram-negative bacteria has proven very difficult in recent decades. Even if increased funding reinvigorates efforts, it is far from certain that sufficient truly novel chemical classes will be discovered. In fact, according to Coates et al the chance that sufficient new classes of antibiotics will be discovered is remote [1].

If it is unlikely the gap will be filled in time to impact significantly on the increase in deaths predicted over the next two decades, then it is essential that we make better use of drugs currently available to fill the gap - not only antibiotics alone and in combinations, but also other drugs that could be used to protect the host against the foreign invader. For certain antibiotics, we may be able to repurpose other classes of drug to break resistance and rescue the antibiotic. Also, often it is not bacteria that kill, it is our body's reaction to the bacteria. Septic shock followed by organ damage and death is caused by precipitous fall in blood pressure, blood coagulation, and by dysregulated response of the immune system to infection. Treatment of bacterial infection and sepsis is currently heavily focused on choice of which antibiotics to use: less attention is paid to modulating the inappropriate host response or tackling the cause of the fall in blood pressure, and actions to protect organs at risk are inadequate. New drug discovery efforts against sepsis have a poor record [2], but there is major opportunity to introduce rapidly new treatments by repurposing drugs already available for clinical use. This could 'fill the gap' by reducing use of antibiotics, slowing development of resistance, and save many lives.

Five very practical repurposing approaches to save lives are summarised in this chapter.

The first opportunity is to assess the effectiveness of beta-lactam antibiotics when combined with any two of the several resistance-breaking betalactamase inhibitors or dehydropeptidase inhibitors available for use. This option has been exploited only in a single combination so far, which leaves ample scope for introduction of new triple combinations (antibiotic plus two non-antibiotic resistance breakers) to break resistance against our most precious beta-lactam antibiotics.

The second opportunity is a rigorous investigation of combinations of two or more antibiotics, particularly by including those that modulate host defense and protect organs from damage. Physicians often resort to use of combinations or to sequential antibiotics, yet the scientific evidence for their use is poor. Again, only a single example of this approach being exploited exists today: only one combination of two antibiotics effective against lethal Gramnegative bacteria has been developed and approved by regulatory authorities. This represents a massive gap that could be filled by repurposing current 
antibiotics in rigorously-proven combinations to extend their usefulness against resistant bacteria.

The third opportunity is to explore greater use of bacteriostatic antibiotics either alone or in combinations. This could side-step the growing issue of bacteria resistant to carbapenems. It might also help to reduce tissue damage in severe infections that lead to septic shock by not releasing bacterial components that can exacerbate inflammation and result in damage to vasculature and many internal organs. This option becomes increasingly practical if organ-protecting strategies acting via host-mechanisms are also implemented. This might be our only practical chance of beating the growing threat from carbapenem-resistant bacteria.

The fourth opportunity is to repurpose non-antibiotic drugs for treatment of sepsis. Septic shock is often the ultimate outcome of infection, leading to organ damage and failure, loss of limbs, disfigurement and a high death rate. Advances in medical science in recent years are not reflected in current treatment of sepsis, and earlier clinical trials have given extremely disappointing results [2]. Understanding the inappropriate immune activation, inflammation, vascular leakage, organ damage and blood clotting that leads to these sad outcomes can point to opportunities to repurpose safe drugs to protect the infected person from damage. These repurposed non-antibiotic drugs could be used alongside antibiotics in treatment of sepsis, and very likely lead to a significant reduction in use of antibiotics.

The fifth opportunity is to extend use of macrolides and tetracyclines in combination with other antibiotics to protect patients against the consequences of bacterial infection. These drug classes have additional hostdefense properties in addition to their antibiotic effects. There is considerable clinical evidence in several types of bacterial infection that their use can lead to lower death rates than would be expected. Rigorous examination of the best combinations could reinvigorate therapeutic options. 


\subsection{WHY DEATHS WILL INCREASE BEFORE THE ANTIBIOTIC GAP IS FILLED}

\subsubsection{Current actions are too little and too late}

In recent years, many publications have highlighted the growing risk to humanity from the ESKAPE pathogens (Enterococcus faecium, Staphylococcus aureus, Klebsiella pneumoniae, Acinetobacter baumannii, Pseudomonas aeruginosa, and Enterobacter species) [3]. Resistance levels of up to $50 \%$ have been reported in some developing countries against carbapenems, the current last line of defence [4]. A few new classes of antibiotics against Gram-positive bacteria have become available in recent decades. However, for treatment of Gram-negative infections no totally new class of antibiotic has been introduced for over forty years, only modifications of older antibiotics, against which bacteria have been able to develop resistance quite rapidly. All chemical classes of antibiotics useful against Gram-negatives were discovered in the 1930s-1960s, none since then. Figure 1 shows the date of introduction of each new class of antibiotic since the sulphonamides in the 1930s.

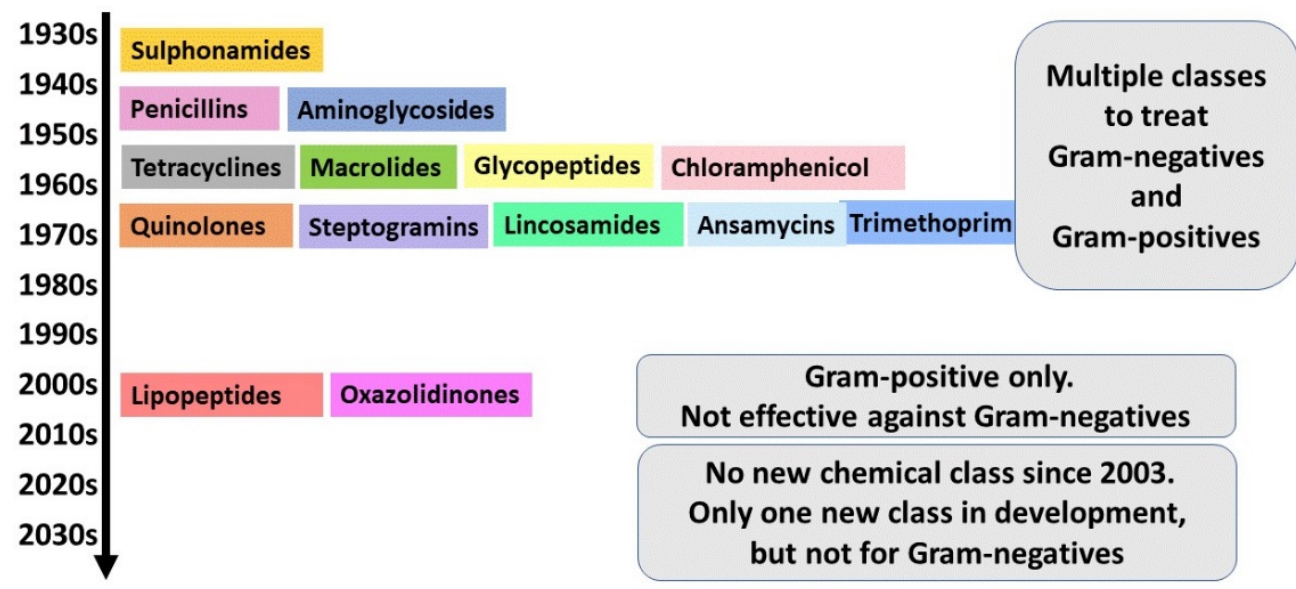

Figure 1. Date of introduction of each new class of antibiotic

Why is it more difficult to invent new chemical classes effective against Gramnegative than Gram-positive bacteria? Gram-positives have a single cell membrane that antibiotics must penetrate to gain access to the bacterial cell. Gram-negative bacteria contain an additional barrier, a cell wall outside the inner membrane, the two together being called the 'envelope'. Moreover, this second barrier has very different physicochemical properties than the inner membrane, which increases the difficulty of discovering antibiotics effective 
against Gram-negatives. There is significant doubt that we can deliver new antibiotics for Gram-negatives at the rate required in coming decades.

UK Chief Medical Officer Dame Sally Davies has been a global leader in highlighting the antibiotic resistance issue and in 2014 the UK government initiated a review of the seriousness of the problem. Jim O'Neill led a team that conducted an in-depth review of antibiotic resistance. The diagram below is taken from the first report from his team, issued in December 2014, titled 'Antimicrobial Resistance: Tackling a crisis for the health and wealth of nations' [5]. His team was staffed mostly by economists (his own background) and Figure 2 shows the predicted loss in World GDP in coming decades due to antimicrobial resistance. The exponential loss in global wealth is also mirrored in a similar prediction of exponential loss of lives. The O'Neill review predicted that deaths from antimicrobial resistance could overtake those from cancer in the 2040s.

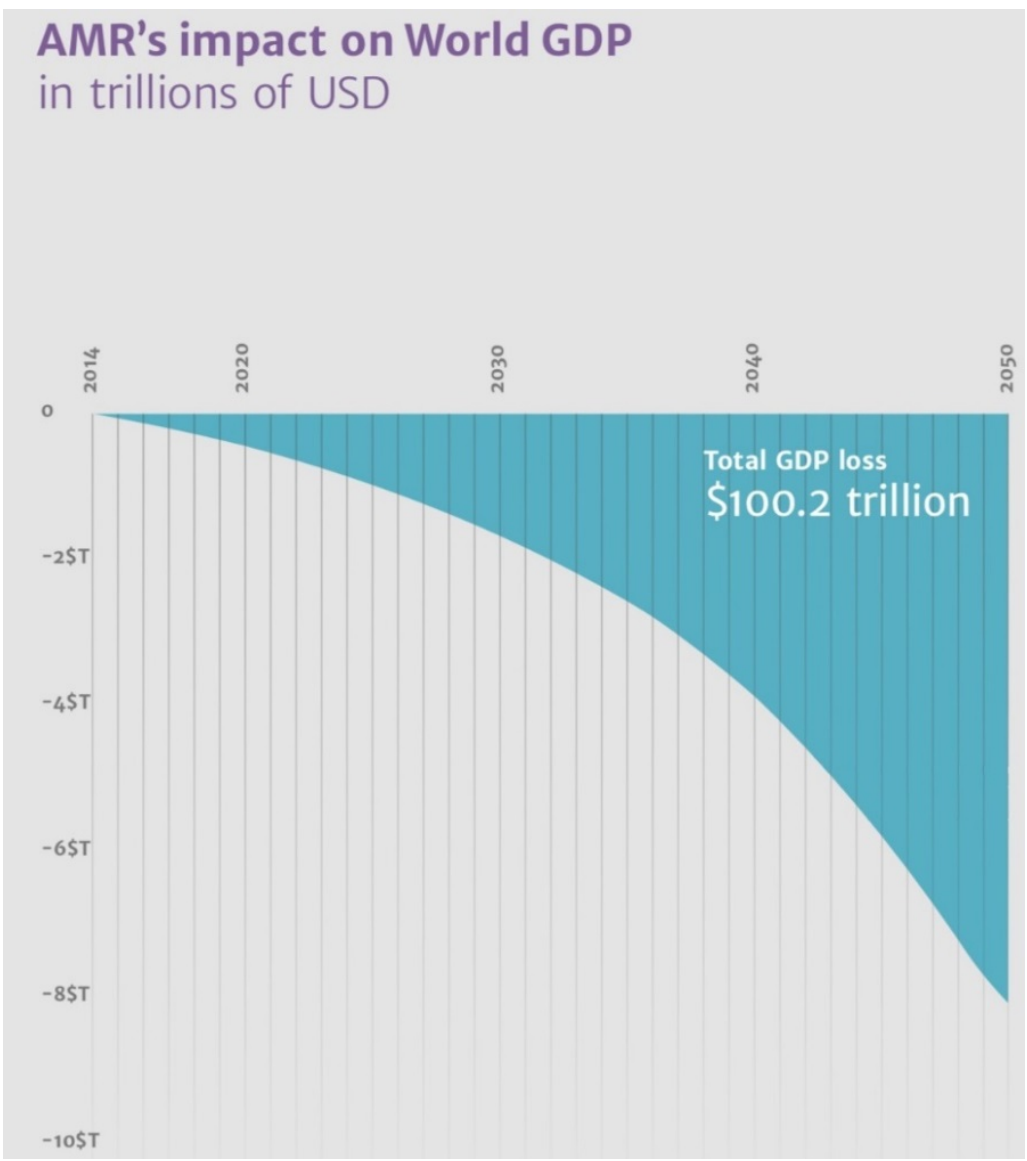

Figure 2. Predicted impact of AMR. Increase in deaths and reduction in global GDP [5]. 
The 2040s are only a quarter century away which is a short time when one remembers that timelines for drug development are measured in decades and we have already failed for 40-years to invent new antibiotics effective against Gram-negative bacteria. As Coates et al. [1] stated, a big gap in the antibiotic pipeline is guaranteed. Some governments have now started to increase public funding for antibiotic research, yet many problems remain: the amount of funding available is small in comparison with that spent in other disease areas; the global skill base is weak due to previous under-investment; clinical development is challenging; and the commercial model for antibiotics remains unsolved despite much debate about the current broken model.

A recent report titled 'Incentivising innovation in antibiotic drug discovery and development: progress, challenges and next steps' by Simpkin etal. [6] assessed the major international, European Union, US and UK antibiotic R\&D funding programmes. They found that incentive programmes are overly committed to early-stage push funding of basic science and preclinical research, while there is limited late-stage push funding of clinical development. Moreover, there are almost no pull incentives to facilitate transition of antibiotic products from early clinical phases to commercialisation, or to focus developer concentration on the highest priority antibiotics, or to attract large pharmaceutical companies to invest in the market.

\subsubsection{Limitations of the current antibiotic pipeline}

Also, the current pipeline of antibiotics is a major concern. According to the latest pipeline overview reported by the Pew Trust [7] updated to September 2017, 48 antibiotics with the potential to treat serious bacterial infections were identified in clinical development for the U.S. market. The number may sound encouraging but a deeper look at the compounds and their profiles reveals 'more of the same'. Perhaps the most valuable information in the report is that only 1 of the 48 represents a potential breakthrough. Only Murepavadin was listed as representing a novel drug class, defined as a core chemical structure (scaffold) that has not previously been used systemically as an antibacterial in humans, while also hitting a novel molecular target (a target is defined as novel if the drug acts on a bacterial structure that has not previously been targeted by a systemic antibacterial in humans.) It is in phase 2 clinical trials for the narrow indication of treatment of ventilator-associated bacterial pneumonia due to Pseudomonas aeruginosa. Apart from this single example, all other antibiotics identified in the report do not target the ESKAPE pathogens by a new chemical class and new biochemical target.

Historical data indicates that the success rate for clinical drug development of antibiotics is low. Generally, only 1 in 5 infectious disease products that enter human testing (phase 1 clinical trials) will be approved for patients. Another 
concern is that even for new classes of antibiotic, resistance can develop very rapidly, within 2 years of marketing according to Bax et al. [8].

One more point should be made before closing this section. Several authors have stated that the greatest threat to humanity comes from carbapenemresistant Enterobacteriaceae (CRE) [9]. This form of resistance is appearing in many genera including familiar pathogens such as E. coli, Salmonella, Yersinia pestis (plague), Klebsiella, and Shigella (dysentery). Bacteria that have acquired resistance to both carbapenemases and ESBLs can be resistant not just to carbapenems but to almost all available beta-lactams, our most widely used class of antibiotic. It is unclear whether any of the antibiotics in the pipeline address this major concern. The seriousness of the issue is illustrated in Figure 3, kindly provided by Dr John Rex.

\begin{tabular}{|c|c|c|c|}
\hline Bacteria (WHO category) & WHO (2017) & CDC (2013) & ESKAPE (2008-9) \\
\hline Acinetobacter baumannii, carbapenem- $R$ & Critical & Serious (MDR) & Yes \\
\hline Pseudomonas aeruginosa, carbapenem- $R$ & Critical & Serious (MDR) & Yes \\
\hline Enterobacteriaceae, carbapenem- $R$, $3^{\text {rd }}$-gen ceph- $R(E S B L+)$ & Critical & $\begin{array}{l}\text { Urgent (carbapenem-R) } \\
\text { Serious (ESBL+) }\end{array}$ & Yes \\
\hline Enterococcusfaecium, vancomycin- $\mathrm{R}$ & High & Serious (VRE) & Yes \\
\hline Staphylococcus aureus, methicillin- $R$, vancomycin- $1 / R$ & High & $\begin{array}{c}\text { Serious (MRSA) } \\
\text { Concerning (VRSA) }\end{array}$ & Yes \\
\hline Helicobacter pylori, clarithromycin- $\mathrm{R}$ & High & & \\
\hline Campylobacter spp., fluoroquinolone- $\mathrm{R}$ & High & Serious (drug- $\mathrm{R}$ ) & \\
\hline Salmonellae spp., fluoroquinolone- $\mathrm{R}$ & High & Serious (drug- $\mathrm{R}$ ) & \\
\hline Neisseria gonorrhoeae, $3^{\text {rd }}$-gen ceph- $\mathrm{R}$, fluoroquinolone- $\mathrm{R}$ & High & Urgent (drug-R) & \\
\hline Streptococcus pneumoniae, penicillin-NS & Medium & Serious (drug- $\mathrm{R}$ ) & \\
\hline Haemophilus influenzae, ampicillin- $R$ & Medium & & \\
\hline Shigella spp., fluoroquinolone- $\mathrm{R}$ & Medium & Serious & \\
\hline Clostridium difficile & & Urgent & \\
\hline Candida spp. fluconazole- $\mathrm{R}$ & & Serious (Flu-R) & \\
\hline M. tuberculosis & & Serious (drug- $\mathrm{R}$ ) & \\
\hline Group A Streptococcus & & Concerning (erythro-R) & \\
\hline Group B Streptococcus & DC, \& ESKAPE & Concerning (clinda- $\mathrm{R}$ ) & 2 \\
\hline
\end{tabular}

Figure 3. WHO priority pathogen list for R\&D (http://amr.solutions/blog/who-priority-pathogens-list) 


\subsection{REPURPOSING ANTIBIOTICS: ANTIBIOTIC COMBINATIONS TO BREAK RESISTANCE}

With this serious situation, it is essential that we take urgent action to save our best antibiotics. When bacteria develop resistance to an antibiotic it may be possible to break that resistance and make the antibiotic effective again by adding a second drug molecule. There are several categories of drug molecule that might be used:

1) for beta-lactam antibiotics, use in combination with one or more additional (non-antibiotic) beta-lactamase inhibitors to prevent degradation of the antibiotic by bacteria,

2) for all antibiotics, addition of a second antibiotic,

3) combinations of bacteriostatic antibiotics to side-step MBLs and CREs.

\subsubsection{Beta-lactams combined with one or two beta-lactamase inhibitors}

Combinations of a beta-lactam antibiotic and a single lactamase inhibitor are receiving a lot of attention. Several combinations of this type are available onthe-market or in clinical development, as shown in Table 1.

Table 1. Antibiotics combined with a single beta-lactamase or DHP inhibitor

\begin{tabular}{ccc}
\hline $\begin{array}{c}\text { Antibiotic + beta-lactamase } \\
\text { inhibitor }\end{array}$ & $\begin{array}{c}\text { Route of } \\
\text { administration: } \\
\text { intravenous or } \\
\text { oral }\end{array}$ & $\begin{array}{c}\text { Market year or } \\
\text { clinical } \\
\text { development stage }\end{array}$ \\
\hline ampicillin / sulbactam & iv; po & 1987 \\
\hline amoxycillin / clavulanic acid & iv; po & 1984 \\
\hline cefoperazone / sulbactam & iv; po & Not-approved \\
\hline ceftazidime / avibactam & iv & 2015 \\
\hline ceftozolane / tazobactam & iv & 2015 \\
\hline imipenem / cilastatin (DHP) & iv & 1987 \\
\hline piperacillin / tazobactam & iv & 1993 \\
\hline ticarcillin /clavulanic acid & iv & 1990 \\
\hline meropenem + vaborbactam & iv & FDA approval 2017 \\
\hline imipenem/ cilastatin + & iv & Clinical Phase 3 \\
relebactam & iv & Clinical Phase 2 \\
\hline aztreonam + avibactam & iv & Clinical Phase 1
\end{tabular}


Those in clinical development generally have reasonable potency against $E$. coli and $K$. pneumoniae but they are much less effective (or not effective at all) against $P$. auruginosa and $A$. baumannii. Effective treatment of these bacteria remains a major issue.

The triple combination comprising imipenem with the beta-lactamase inhibitor relebacatam and the dehydropeptidase inhibitor cilastatin is the first example of the interesting idea of using two resistance breakers in combination with an antibiotic. There is considerable scope to explore this further, for instance by assessing the effectiveness of beta-lactam antibiotics combined with any two of the several beta-lactamase inhibitors available for use. Drugs with related chemical structures acting on the same target often bind that target in subtly different ways, so combining two similar-looking beta-lactamase inhibitors could be unexpectedly effective in blocking degradation of beta-lactam antibiotics.

A related idea, currently totally unexplored in the literature, is to combine two antibiotics and a beta-lactamase inhibitor. The number of possible combinations is huge, and it seems quite likely that combinations able to overcome bacterial resistance could be found.

The next section explores the status of combinations of antibiotics.

\subsubsection{Antibiotics combined with a second or third antibiotic}

Category 2 has received much less attention. Table 2 shows the available combinations of two antibiotics and Table 3 shows the single example of a combination of three antibiotics, although this is for topical use only.

Table 2. Antibiotics combined with a second antibiotic

\begin{tabular}{ccc}
\hline ampicillin + flucloxacillin & po & $\begin{array}{c}\text { Not Gram-negatives } \\
\text { Used for cellulitis due to Gram-positive } \\
\text { staphylococcus and streptomyces }\end{array}$ \\
\hline bacitracin/polymyxin B & topical & Eye infections \\
\hline $\begin{array}{c}\text { co-trimoxazole } \\
\text { trimethoprim+sulfamet } \\
\text { hoxazole) }\end{array}$ & oral & $\begin{array}{c}\text { The only systemic acting double } \\
\text { combination against Gram-negatives }\end{array}$ \\
\hline $\begin{array}{c}\text { phenoxymethylpenicillin } \\
\text { /pipacycline } \\
\text { (Penimepicycline) }\end{array}$ & oral, im & $\begin{array}{c}\text { Weak against Gram-negatives } \\
\text { Salt formed between a tetracycline and a } \\
\text { penecillin }\end{array}$ \\
\hline $\begin{array}{c}\text { quinupristin/dalfopristin } \\
\text { (Synercid) }\end{array}$ & iv & $\begin{array}{c}\text { Both are pristinamycin analogues } \\
\text { Used against staphylococci and } \\
\text { vancomycin-resistant Enterococcus } \\
\text { faecium }\end{array}$ \\
\hline
\end{tabular}


Table 2. (continued)

\begin{tabular}{ccc}
\hline $\begin{array}{c}\text { mikamycin B / } \\
\text { streptogramin A } \\
\text { (pristinamycin) }\end{array}$ & oral & Not Gram-negatives \\
\hline $\begin{array}{c}\text { virginiamycin / } \\
\text { pristinamycin }\end{array}$ & po & Animal feed \\
\hline
\end{tabular}

Table 3. Antibiotic combined with a second and third antibiotic

Tables 2 and 3 are notable in several respects. Despite the large numbers of antibiotics available (over 100) and the even-larger number of possible combinations (many thousands), there are few entries in the table. Moreover, only one entry has efficacy against Gram-negative bacteria. Co-trimoxazole became available in 1974, but no other combination of two antibiotics effective against Gram-negative bacteria has become available since then.

In severe infections, physicians often prescribe two or more antibiotics to patients either together or in sequence, yet most of those combinations have not been rigorously proven to be effective in human clinical trials nor approved by regulatory authorities. This use of unproven combinations may be contributing to the widespread development of resistance to antibiotics.

In addition, the lack of available proven combinations represents a massive gap in development of antibacterial treatments. If more combinations could be developed it could help address the pipeline gap. However, the Pew Trust report of antibiotics being developed [7] contained no combinations of two or more antibiotics.

Combinations of antibiotic plus non-antibiotic has been the subject of considerable academic research and publications yet none of these combinations are registered for use and commercially available today. Companies such as UK-based Helperby Therapeutics have products in early-tomid stage clinical development [10] though it is unclear whether these will achieve clinical success for the most serious Gram-negative infections.

Combinations of already approved drugs can be simpler to develop than a new chemical entity. Many factors which are a risk in development of a totally new drug are substantially derisked when old drugs are repurposed: for each individual drug, pharmacokinetics and distribution in the body are known; the safety profile is known; the dose required for efficacy is known etc. However, when two drugs are used in combination, drug-drug interactions need investigating to assess whether any of these parameters change. In a positive sense, if a synergist effect is achieved between two drugs, this can enable us to reduce drug levels for greater safety, or to maintain drug levels to overcome 
bacterial resistance. Ideally, we would want to avoid using higher doses than those currently approved for use.

An advantage of finding unexpected synergy between two known antibiotics would be the potential to obtain a stronger patent position. This could be important for commercial return to the manufacturer.

Combinations are used extensively against other infectious diseases (TB, AIDS, Hep C) to prevent and overcome resistance, yet they have been largely ignored for antibiotics. One issue though is that the number of possible combinations and required assays is huge when one considers the large number of possible antibiotics (or even non-antibiotics), the large number of pathogenic bacteria, and the large number of resistant strains that develop for each type of bacterium. So, it is fortunate that new informatics methods are being developed based on Machine Learning to predict combinations that could be effective against specific resistant strains [11]. Also, testing protocols have been proposed which reduce the number of assays when compared with the traditional chequerboard method, which can be very expensive and logistically prohibitive for higher-order interactions [12-15].

In summary, there is a clear unmet need to develop antibiotic combinations to salvage our best antibiotics and preserve their usefulness during the decades before new chemical classes of antibiotic become available. Particularly, there is terrific opportunity for rigorous development of combinations of two or more antibiotics that are effective against resistant species of Gram-negative bacteria. These alone could go a long way towards filling the pipeline gap and reducing the extraordinary increase in death rates predicted by the $0^{\prime} \mathrm{Neill}$ Review.

\subsubsection{Combinations of bacteriostatic antibiotics to side-step MBLs and CREs and reduce organ damage in septic shock}

Antibiotics are broadly classified into those that kill bacteria ('cidal) and those that reduce growth with reliance on the immune system to clear them ('static). There may be an assumption that bactericidal antibiotics are more effective in curing patients, however this has not been rigorously tested and it is possibly inaccurate. Recently, Nemeth et al. conducted the first ever meta-analysis of trial data comparing 'cidal and 'static antibiotics. Their analysis showed no difference in outcomes for 'cidal versus 'static antibiotics in infections affecting lungs (pneumonia), abdomen and soft tissue [16]. There was insufficient data to assess infections of brain (meningitis) and heart (endocarditis).

The bactericidal antibiotics include aminoglycosides, beta-lactams, quinolones, glycopeptides and lipopeptides; whereas the bacteriostatic antibiotics include the tetracyclines, lincosamides, macrolides, oxazolidinones, streptogramins and sulphonamides. Bactericidal antibiotics are generally recommended for 
patients with a compromised immune system (such as neutropenia) yet the analysis by Nemeth et al. did not support the assumption of inferior outcomes if bacteriostatics were used. In addition, the assumption that relapse rates will be higher with bacteriostatic antibiotics was challenged by their analysis.

The emerging crisis of CRE's and bacteria expressing ESBLs and MBLs seems unlikely to be contained by invention of sufficient classes of beta-lactam antibiotics in coming decades [11]. Alternative approaches need testing urgently. If host-mediated mechanisms can be exploited to boost host defence and protect organs, the improved therapeutic options might include replacement of bactericidal antibiotics such as beta-lactams, aminoglycosides, and quinolones with bacteriostatic antibiotics such as macrolides, tetracyclines and sulphonamides. This requires testing.

\subsection{REPURPOSING NON-ANTIBIOTIC DRUGS TO PREVENT ORGAN DAMAGE AND DEATH FROM SEPSIS}

Bacterial infection can cause sepsis then septic shock (development of severe hypotension and blood coaggulation leading to multi-organ failure) which often is the ultimate killer. The sequalae are shown in Figure 4.

Once septic shock sets in, death rates are high. The global burden of sepsis is estimated to be 15-19 million cases annually, with a mortality rate of 20-50\% in developed countries and approximately $60 \%$ in low-income countries [17]. The probability of death increases by approximately $10 \%$ for each hour the condition is unrecognised or treated ineffectively.

Sepsis is a complex condition characterized by the simultaneous activation of inflammation and coagulation in response to bacterial infection. These events manifest as systemic inflammatory response syndrome (SIRS) and other symptoms through the release of proinflammatory cytokines, procoagulants, and adhesion molecules from immune cells and/or damaged endothelium. Hypoperfusion due to low blood pressure leads to organ dysfunction and failure, and to blood clotting and extensive formation of thrombi. Dysfunction of respiratory and cardiovascular systems is common, and brain and kidneys are also often affected. Systemic thrombocytopenia leads to disseminated intravascular coagulation (DIC) and survivors often have organ damage or loss of limbs, disfigurement, impaired neurocognitive function, mood disorders, and a poor quality of life. Clinical studies have shown that up to $60 \%$ of sepsis survivors exhibit permanent cognitive deficits and memory loss [18]. Survivors also have an increased risk of death in the following months and years [19]. 


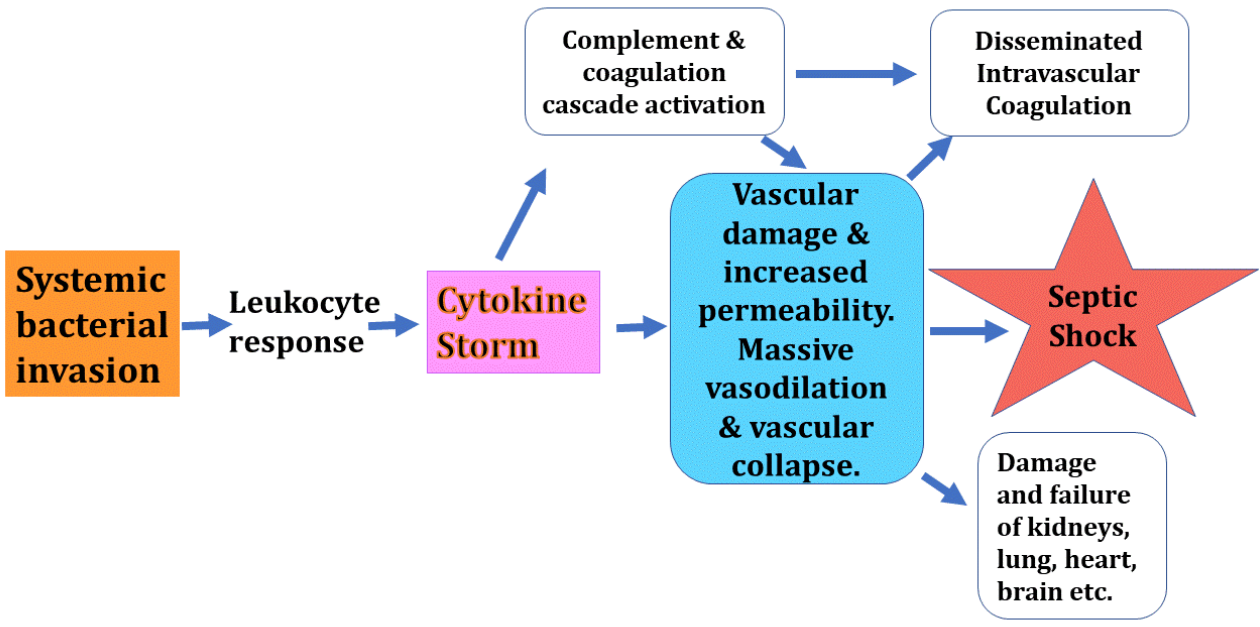

Figure 4. Bacterial invasion leading to septic shock

Treatment of sepsis is currently limited to use of antibiotics plus supportive measures such as use of vasopressive drugs and non-specific antiinflammatory steroids [20]. The proximal host-response factors that lead to the severe hypotension, coaggulation and inflammation are not treated directly, only the symptomology.

Severe sepsis occurs from both community-acquired and nosocomial (hospital acquired) infections. In about one-half of all cases the primary site of infection is the lung (pneumonia). Other major sites are the abdomen and the urinary tract [21-23]. The ESKAPE pathogens are the most common causes: Grampositives Staphylococcus aureus and Streptococcus pneumoniae, and Gramnegatives Escherichia coli, Klebsiella species, and Pseudomonas aeruginosa.

A 2009 study involving 14,000 intensive care unit (ICU) patients in 75 countries, indicated that Gram-negative bacteria were isolated in $62 \%$ of patients with severe sepsis who had positive cultures, Gram-positive bacteria in $47 \%$, and fungi in $19 \%$. The figures suggest multiple infections can be present [23].

Since current treatments do not target the mechanistic cause of sepsis syndrome, this likely makes antibiotic treatment much less effective than it could be if more-specific interventions were used. Also, this likely leads to generation of more antibiotic resistance than would otherwise occur if the causes of septic shock could be rectified more directly and more rapidly.

Angus and Poll [24] have provided an excellent review of pathways involved in sepsis, and D'Elia etal. [25] have described the 'cytokine storm' that is characteristic of septic shock. The key cellular and biochemical changes driven 
by presence of bacteria in the blood stream, lungs or peritoneal cavity include the activation of macrophages and monocytes, with tumor necrosis factoralpha (TNF- $\alpha$ ), interleukin-1 $\beta$ (IL-1 $\beta$ ), interleukin-6 (IL-6) and interleukin-8 (IL-8) particularly involved in the development of septic shock. However, the precipitous drop in blood pressure might be cause by another factor, reviewed in the next section.

\subsubsection{Vitamin C, thiamine and hydrocortisone triple therapy}

Clinical evidence for use of high dose vitamin $\mathrm{C}$ alongside standard therapy for treatment of sepsis has generated considerable interest and controversy recently. An excellent 2018 review of the pharmacological actions of vitamin C and clinical data for its use in sepsis patients has been provided by Teng et al. [26]. At the present time, based on studies in animals and a small number of patient outcomes, it appears to be a promising therapy though definitive double blind clinical trials are lacking.

The underlying hypothese is as follows. Vitamin $\mathrm{C}$ is an essential cofactor in the biochemical synthesis of several vascular pressor agents that maintain blood pressure, including vasopressin and the catecholamines adrenaline (epinephrine) and dopamine. Lethal drop in blood pressure is the defining characteristic of bacterial septic shock and low levels of both vitamin $\mathrm{C}$ and the pressor agents have been observed in critically-ill patients. Levels of vasopressin and vitamin $\mathrm{C}$ deplete as a patient progresses into hypotension and shock [27-30]. It has been known for over 2 decades that the low plasma ascorbic acid concentrations in septic patients correlate inversely with the incidence of multiple organ failure and correlate with survival rates [31]. The low levels of vitamin $C$ in septic patients has been attributed to several factors including its destruction by free radicals [32].

Vitamin $\mathrm{C}$ acts as co-factor for the enzyme peptidylgylcine alpha-amidating monooxygenase (PAM), which is required for the synthesis of vasopressin [33].

Vitamin $C$ is also a cofactor in two steps in the synthesis of dopamine and adrenaline. Figure 3 from Zipursky et al. [34] describes the biochemical pathway. Vitamin C is involved in the rate-limiting step of synthesis of L-DOPA, the precursor of dopamine and it is also required as a cofactor for the enzyme dopamine beta hydroxylase [33] which converts dopamine to adrenaline (epinephrine). Adrenaline is a critical vasopressor for septic patients through its action on both alpha and beta-adrenergic receptors to maintain vascular tone and increase cardiac output. 


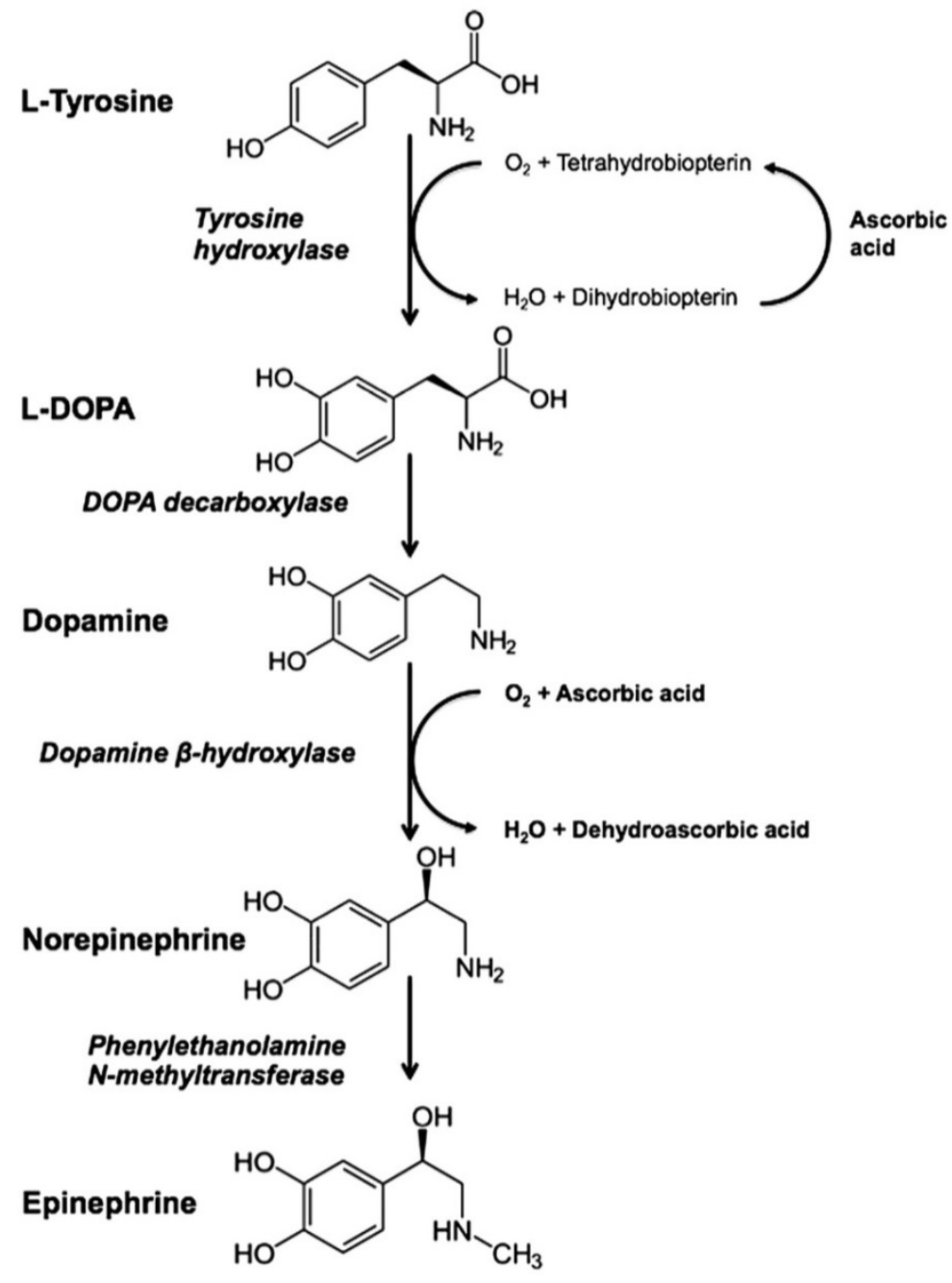

Figure 3. Vitamin C (ascorbic acid) is required to synthesize catecholamines ${ }^{34}$

As an additional factor, vitamin $\mathrm{C}$ binds to and modulates function of both alpha-adrenergic and beta-adrenergic receptors and enhancing their activation by adrenaline / epinephrine [35].

Current treatment of sepsis [36] includes exogenous administration of noradrenaline (norepinephrine), adrenaline and vasopressin as necessary to maintain blood pressure, and several authors have argued that intervention to raise plasma vitamin $\mathrm{C}$ levels in septic shock patients might provide an effective replacement [33]. 
Vitamin C also has effects on the immune system. It is found in high concentration in leukocytes [37] and it amplifies in oxidative neutrophilic killing of bacteria by leukocytes [38]. Deficiency in vitamin C was associated with delayed killing of bacteria by natural killer (NK) cells and suppressed cytotoxic T cell activity [39] It inhibits tumour necrosis factor (TNF)-induced production of intercellular adhesion molecules (ICAMs), which decreases leukocyte stickiness and improves microcirculatory flow $[39,40]$.

Additionally, vitamin $\mathrm{C}$ has been shown to support immune function by inhibiting apoptosis and protecting endothelial progenitor cells [41,42]. High dose vitamin $\mathrm{C}$ can decrease NF-kB leading to modulation of an over-active immune response [43].

In 2001, an early indication of the potential efficacy of high dose vitamin $C$ in treatment of septic shock was provided by Armour et al. [44]. They showed that in a cecal ligation and perforation (CLP) rat model, plasma vitamin C levels plummeted by $50 \%$ with a concomitant increase of 1,000 \% in urine ascorbate concentration. This was accompanied by a $20 \%$ decrease in mean arterial pressure, and a $30 \%$ decrease in the density of perfused capillaries. These changes could be reversed with a bolus of intravenous ascorbate (7.6 mg/100 g body weight) administered immediately after the CLP procedure. They also showed that these high plasma levels of ascorbate might have direct killing effects on bacteria: in vitro experiments showed that ascorbate $(100 \mu \mathrm{M})$ inhibited replication of bacteria and prevented hydrogen peroxide injury to cultured microvascular endothelial cells. The authors concluded that their studies supported a potential beneficial effect of ascorbate in patients with septic syndrome.

A series of papers from Wu et al. linked the action of ascorbate to inhibition of iNOS expression followed by reduction in peroxynitrite formation and its negative effects on endothelial function [45-48]. Working with one of the ESKAPE pathogens, in 2006 Gaut et al. reported that mice with vitamin C deficiency had a 3-fold increase in rate of death from Klebsiella pneumoniae infection versus those supplemented with ascorbate [49].

More recently in 2011, in a mouse model vitamin C was shown to attenuate lipopolysaccharide (LPS) mediated lung injury during sepsis [50].

Then in 2012, Zhou et al. showed in a CLP model that high dose vitamin C given 3 hours after CLP prevented an increase in vascular permeability and leakage by inhibiting excessive production of NO, superoxide and peroxynitrite [51].

One potential issue with animal studies using vitamin $C$ is that most animals, including rats and mice, can synthesise their own vitamin $C$, whereas humans lack that capability - our vitamin $\mathrm{C}$ must come from exogenous sources such as food or supplements. Fisher et al. used a mouse model in which the genes governing vitamin $\mathrm{C}$ synthesis had been deleted, to more closely resemble the human situation [52]. They then induced sepsis in these mice by 
intraperitoneal infusion of a fecal stem solution. This produced injury to lungs, kidneys and liver in vitamin $\mathrm{C}$ deficient mouse, but the mice dosed with exogenous vitamin $C$ had reduced multiple organ dysfunction. Moreover, the gene-deleted mice developed significant abnormalities in the coagulation system and circulating blood cells. These were attenuated by vitamin C infusion. The protective action of vitamin $\mathrm{C}$ on vascular endothelium has also received attention $[53,54]$.

In parallel with these in vitro and animal studies, evidence has accumulated in human studies to show a protective effect of high dose vitamin $\mathrm{C}$ against severe organ damage and bacterial infection. In 2002 Nathens et al. enrolled 595 patients, mostly victims of trauma [55]. They showed that multiple organ failure was significantly less likely to occur in patients receiving a combination of ascorbic acid and alpha-tocopherol (vitamin E) than in patients receiving standard care, with a relative risk of 0.43 . Patients randomized to antioxidant supplementation also had a shorter duration of mechanical ventilation and length of ICU stay. Crimi et al. reported similar findings [56].

The animal studies with vitamin $C$ in sepsis models aroused interest in human clinical trials. Wilson (2013) [57] and Carr et al. (2015) [58] summarised the rationale for testing vitamin C in a randomised clinical trial. In 2014, Fowler et al. reported a Phase 1 safety study with high dose parenteral vitamin $C$ in 24 patients with severe sepsis [59]. In the septic patients, plasma ascorbic acid levels at entry were about one-third normal levels $(17.9 \pm 2.4 \mu \mathrm{M}$ compared to a normal range of 50-70 $\mu \mathrm{M}$ ). Infusion of high dose vitamin $\mathrm{C}$ (up to $200 \mathrm{mg} \mathrm{kg}^{-1} / 24 \mathrm{~h}$ ) raised plasma levels rapidly without any significant adverse events. Patients receiving the vitamin $C$ showed rapid improvement in Sepsis-related Organ Failure Assessment (SOFA) symptomatic score. They also had significant reduction in the proinflammatory biomarkers C-reactive protein and procalcitonin. Moreover, in the treated patients thrombomodulin exhibited no significant rise, suggesting attenuation of vascular endothelial injury.

In 2016 Zabet et al. evaluated the effect of high-dose ascorbic acid on vasopressor drug requirement in critically ill patients with septic shock [60].

In 14 treated patients compared to 14 untreated controls, 28-day mortality was significantly lower in the ascorbic acid than the placebo group (14.28 \% vs. $64.28 \%$, respectively; $\mathrm{P}=0.009$ ).

Then in 2017, Marik et al. reported results of a phase 2 trial in patients with severe sepsis [61]. 47 septic controls receiving normal care, including antibiotics, norepinephrine and hydrocortisone, were retrospectively compared with 47 septic patients additionally treated with intravenous vitamin $\mathrm{C}$, hydrocortisone, and thiamine (the thiamine was included to reduce concerns about oxalic acid formation in kidneys from the high vitamin $\mathrm{C}$ doses used, and because thiamine deficiency is common in sepsis, occurring in 
approximately one-third of patients and associated with increased mortality [62].)

During the treatment period patients with severe sepsis or septic shock and a procalcitonin level $>2 \mathrm{ng} \mathrm{mL}^{-1}$ were treated with intravenous vitamin $\mathrm{C}(1.5 \mathrm{~g}$ every $6 \mathrm{~h}$ for 4 days or until ICU discharge), hydrocortisone (50 mg every $6 \mathrm{~h}$ for 7 days or until ICU discharge followed by a taper over 3 days), as well as intravenous thiamine ( $200 \mathrm{mg}$ every $12 \mathrm{~h}$ for 4 days or until ICU discharge). The vitamin $\mathrm{C}$ was administered as an infusion over 30-60 min and mixed in a $100 \mathrm{~mL}$ solution of either dextrose $5 \%$ in water or normal saline. Mortality was $8.5 \%$ ( 4 of 47 ) in the treatment group compared with $40.4 \%$ (19 of 47) in the control group $(\mathrm{P}<0.001)$. No patient in the treated group developed progressive organ failure, allowing all patients in the treatment group to be weaned off vasopressors at a mean of time of $18.3+/-9.8 \mathrm{~h}$ after starting treatment with the vitamin $\mathrm{C}$ protocol.

This was not a blinded random clinical trial and so additional studies are required to confirm these preliminary findings. The publication of these results has sparked intensive debate around the study design, which the authors accept needs upgrading in later studies. To strengthen the case, Marik has more recently stated:

"We have now treated over 150 patients with severe sepsis and septic shock. We have had only one patient die from sepsis, this being a complex surgical case who died in the immediate post-operative period. While a few of the treated patients have died, none died from progressive organ failure related to sepsis. All these patients were weaned off pressors/mechanical ventilation and died from their underlying disease. There can be no question of doubt that we have changed the natural history and disease progression of patients with sepsis... patients with sepsis simply just don't develop progressive organ failure." [63]

The studies from Marik etal. evaluated the synergistic administration of vitamin $\mathrm{C}$ with hydrocortisone and thiamine, and did not examine vitamin $\mathrm{C}$ monotherapy. Although the study is limited by its open label and single centered design, with small sample size, it did produce a statistically significant result with well-matched controls [64].

When viewed alongside the earlier preclinal data and the clinical studies from Fowler [59] in 2014 and Zabet [60] in 2016, and Marik's own updated report of treatment of a larger number of patients [63], the impression is strengthened that a breakthrough might have been achieved. However, we need at least two random clinical trials to confirm the effect of treatment with high dose vitamin C. We also need to study the relative contributions of the various other agents used, and the best dosage regimes.

Even if eventually proven useful, it seems unlikely that vitamin $C$ will provide full efficacy when larger numbers of patients are studied in other trial centres, and the following sections of this paper review some other readily available 
drugs that could also be considered for use as adjuncts to antibiotic treatment to reduce death rates from sepsis.

One other factor should be considered. If high dose intravenous vitamin $\mathrm{C}$ does prove to be a life-saver in septic patients it may be worthwhile to rethink the accompanying antibiotics. For instance, would bacteriostatic agents be better than the bactericidal antibiotics which are currently used? Bactericidal drugs lead to bacterial cell lysis and release of inflammatory mediators such as LPS and bacterial DNA, which could be worsening the excessive inflammatory responses during treatment of sepsis. In addition, an over-reliance on betalactam antibiotics is leading to major resistance to this antibiotic class, including the growing concern about CREs mentioned earlier. As the usefulness of non-antibiotic adjunct therapies begins to change overall treatment regimes, there may be a case for revisiting other classes such as those antibiotics which also have immune-modulating actions that are discussed in a later section of this article.

\subsubsection{Imatinib and abl kinase inhibitors}

Vascular endothelial damage is a primary event leading to other pathological symptoms of septic shock. The vascular endothelial barrier breaks down and fluid leaks into the extravascular space. This leads to life-threatening oedema in internal organs including lung, kidney and brain, with multi-organ failure.

Several groups have reported that an FDA-approved anti-cancer drug, the Ablrelated gene (ARG) kinase inhibitor imatinib, can attenuate inflammatory vascular leak. Interest in imatinib was roused initially by the serendipitous observation that the drug reversed pulmonary oedema in some patients [65].

Subsequently, imatinib has been shown to reduce vascular leak induced by a broad range of challenges including thrombin, histamine, vascular endothelial growth factor (VEGF), oxidative stress, and (importantly) LPS which is a component of Gram-negative bacteria cell wall [66]. In a murine model of sepsis imatinib treatment ( $6 \mathrm{~h}$ and $18 \mathrm{~h}$ after induction of sepsis) attenuated vascular leakage in the kidneys and the lungs $24 \mathrm{~h}$ after induction of sepsis [67]. In vivo, it completely prevented mortality in an intravenous LPS mouse model of endotoxemia and lung injury [68] and it protects against LPS-induced acute lung injury with decreased production of pro-inflammatory mediators [69].

Imatinib has proven to protect organs from damage in other murine models: it preserves the integrity of the blood-brain-barrier (BBB) and reduces inflammation by modulating the peripheral immune response [70]. These observations suggest that inhibition of Abl kinases may have therapeutic potential for decreasing the vascular permeability that underlies much of the organ damage in sepsis. Several other inhibitors of this enzyme are available 
(registered as anti-cancer agents) including nilotinib, dasatinib, ponatinib and bosutinib. When used in long-term treatment of tumours, these drugs can sometimes cause edema, possibly due to off-target effects, though the Abl kinase inhibitors are generally well-tolerated, especially imatinib and nilotinib. Moreover, use in treatment of sepsis would be shorter term than use in treatment of cancer. However, no human clinical studies of Abl family kinase inhibitors on vascular permeability in sepsis have been reported.

The underlying physiological mechanism of action is reasonably well established. The Abl family kinases, c-Abl (Abl1) and Abl related gene (Arg, Abl2), have well characterized roles in the dynamic regulation of the actin cytoskeleton and cell-cell and cell-matrix junctions [71,72]. Abl kinases phosphorylate several cytoskeletal proteins involved in vascular permeability.

However, imatinib is not totally selective for Abl kinase, and inhibition of other kinases may be involved in its efficacy. For example, PDGF-R kinase is a target of imatinib and other FDA approved class members. Additional studies are warranted to determine the contribution of each of these targets in view of their potential in treatment of inflammatory vascular leak syndromes including sepsis.

\subsubsection{Sildenafil and phosphodiesterase-5 inhibitors}

A growing body of literature describes the organ-protective effects of inhibition of the enzyme phosphodiesterase-5 (PDE5) during severe bacterial infection. This enzyme is the target of drugs developed originally for male erectile dysfunction, such as Viagra. Sildenafil (the active ingredient of Viagra) has a broad range of tissue-protective properties including many organs that are vulnerable to damage during septic shock.

Cadirci et al. in 2011 published the first study in animals that showed sildenafil to be protective when dosed post-operatively in a model of bacterial septic shock [73]. In the rat model of caecal ligation and puncture (CLP)-induced sepsis, they demonstrated that sildenafil treatment attenuates lung and kidney injury due to overproduction of oxidant activity. Histopathological analysis showed significant protection against inflammation. Biochemical analysis showed that sildenafil decreased serum level of TNF- $\alpha$. The authors concluded 'sildenafil is a highly protective agent in preventing lung and kidney damage caused by CLP-induced sepsis via maintenance of the oxidant / anti-oxidant status and decrease in the level of TNF- $\alpha$.'

The same year Carvalho et al. also analysed the effects of sildenafil in the CLP model in rats pretreated with the drug [74]. They confirmed the effect on TNF$\alpha$, and also showed that sildenafil reduced levels of C-reactive protein, IL- $1 \beta$ and IL-6. The anti-inflammatory cytokine IL-10 was increased in the sildenafiltreated animals, demonstrating a protective effect on the vasodilatory sepsis. 
The use of sildenafil appeared to reduce the intensity of the infectious process as total leukocyte and neutrophil counts were lower.

Following these early reports, other groups have investigated PDE5 inhibitors as potential treatment for sepsis. In 2015, a team from the University of Pittsburg, using a mouse CLP model of abdominal sepsis, showed that sildenafil decreased markers of systemic inflammation, protected against organ injury, and increased circulating amounts of tumor necrosis factor receptor 1 (TNFR1) in mice with sepsis [75]. This had the protective effect of limiting inflammation, and the underlying mechanism was reported to be via cyclic guanosine monophosphate (cGMP) signalling. Sildenafil raises levels of cGMP.

The work by Deng et al. effectively linked several strands of evidence for the usefulness of PDE5 inhibitors in treating sepsis. During endotoxemia and sepsis, levels of soluble TNFR1 increase. If TNF- $\alpha$ is neutralised with sTNFR1, this lessens organ damage [76] and mortality in mice with sepsis [77]. The same laboratory had previously demonstrated that toll-like receptor 4 (TLR4)dependent expression of the gene encoding inducible nitric oxide synthase (iNOS) in hepatocytes leads to nitric oxide (NO) production and activation of the cGMP- and protein kinase G (PKG)-dependent activation of TNF alpha converting enzyme (TACE), which cleaves TNFR1 [78]. They showed that drugs such as PDE5 inhibitors which increase plasma and cellular cGMP levels are effective in enhancing receptor shedding, reducing systemic inflammation, and protecting organs from injury in sepsis.

In 2017, other groups confirmed the effects of PDE5 inhibitors. Kovalski et al. confirmed the protective effect of sildenafil in the rat CLP model of sepsis featuring significantly increased levels of plasma nitrate/nitrite $\left(\mathrm{NO}_{x}\right)$, aspartate aminotransferase (AST), alanine aminotransferase (ALT), urea, creatinine, creatine kinase and lactate [79]. At a functional level, the sepsis led to hypotension, hyporesponsiveness to vasoconstrictor, and renal blood flow reduction. Sildenafil reversed many of these parameters, and in particular it increased renal blood flow and reduced the plasma levels of creatinine, lactate and creatine kinase, as well as reducing lung myeloperoxidase. Benli et al. reported that another PDE5 inhibitor, tadalafil, has a protective effect on kidney function in a rat model of sepsis [80].

Other organs that can be damaged during sepsis include heart, lungs and brain. What is the evidence for protection of these organs by PDE5 inhibitors?

Sildenafil was originally developed as a cardioprotective agent before being repurposed for male erectile dysfunction. Although definitive evidence was not obtained at the time of its early clinical development, post-launch data has indicated that the drug has cardioprotective properties. The first evidence was provided in 2002 by Ockaili et al. who reported that in the rabbit sildenafil induces protective effects against ischemia-reperfusion injury, which are mediated by opening of mitochondrial K(ATP) channels [81]. Importantly for 
cardio-protection in sepsis, the protective effect 'was powerful within $30 \mathrm{~min}$ and persisted to a slightly lesser degree $24 \mathrm{~h}$ after administration of the drug.'

Other mechanisms may also come into play in the heart. Fernandes et al. reported that sildenafil protects function of mitochondria in the heart by preventing reactive oxygen species (ROS) generation [82]. Positive effects on mitochondrial function have also been reported by Whitaker et al. who showed that sildenafil treatment can lead to mitochondrial biogenesis following acute kidney injury [83]. Failure of energy production by mitochondria is a major factor in morbidity and mortality from bacterial sepsis so this protective action of sildenafil may be significant.

Kukreja has published a series of studies which expand on the cardioprotective effects of sildenafil including the role of adenosine receptors in its cardioprotective action [84-93].

The only clinical trial reported using sildenafil to treat a severe heart condition in humans is the RELAX trial in Congestive Heart Failure. The drug showed no benefit [94]. A relatively low dose of $20 \mathrm{mg}$ three times a day (TID) was used for the first 12 weeks and this dose was associated with minimal increases in plasma cGMP. The authors concluded that 'while studies in pulmonary arterial hypertension and HFrEF have observed effects on exercise capacity with similar doses and duration of therapy, we cannot exclude the possibility that inadequate dose or duration of PDE-5 inhibition contributed to our findings.'

There are no reported studies on the effect of PDE5 inhibitors on heart function during bacterial sepsis.

In lungs, the 2011 study by Cadirci et al. in the rat CLP model reported that sildenafil treatment reduced the accumulation of inflammatory cells in lungs leading to less lung injury [73]. Other (non-sepsis) studies of lung injury support this effect. The study by Yildirim et al. investiged the protective effects of sildenafil on tissue integrity, oxidant-antioxidant status, and neutrophil infiltration to the inflamed organ in a rat model of bleomycin-induced lung fibrosis. Treatment of animals with sildenafil $\left(10 \mathrm{mg} \mathrm{kg}^{-1}\right.$ subcutaneously for 14 days) was beneficial with regard to prevention of lipid peroxidation, cytokine (IL-1 $\beta$ and TNF- $\alpha$ ) production, neutrophil accumulation, and myeloperoxidase (MPO) activation [95].

In a pig model of sepsis-induced lung injury, Kemper et al. reported that sildenafil administration improved pulmonary hypertension and oxygenation in LPS-induced lung injury but increased shunt fraction and promoted systemic hypotension, an effect that might be deleterious in treatment of sepsis [96]. They concluded 'it remains unclear whether sildenafil may be beneficial in sepsis patients.'

There have been no reports of animal or human studies on the effect in brain of PDE5 inhibitors in sepsis. Two factors may be relevant: PDE5 in neuronal tissue and PDE5 in microglia. It was recently shown that this enzyme does 
occur throughout neuronal tissues (despite earlier doubts) [97] though no studies have been reported on the importance of PDE5 and its inhibitors on neuronal function in sepsis.

In the CNS, microglia have an immune function role similar to that of macrophages in the periphery. Zhao et al. showed that in microglia, sildenafil attenuates LPS-induced pro-inflammatory responses through downregulation of intracellular ROS-relatedMAPK/NF-kB signaling pathways [98]. Sildenafil markedly inhibited iROS production induced by LPS.

Continuing on the theme of the immune system, recent evidence indicates that sildenafil affects both innate and adaptive immune systems in animals and humans. A thorough first review of the new findings has been provided by Kniotek and Boguska [99]. These authors summarised a growing body of evidence that sildenafil exerts immunomodulatory effects. Sildenafil influences proliferation of regulatory $\mathrm{T}$ cells, and production of proinflammatory cytokines and autoantibodies. Sildenafil decreases the levels of proinflammatory cytokines, including TNF- $\alpha$, IL-1, and reduced NK cells activity, and enhances the action of regulatory $\mathrm{T}$ cells. Sildenafil markedly inhibits iROS production induced by LPS. However, the potential immunomodulatory effects of sildenafil in human sepsis remain to be confirmed.

The inflammatory response during sepsis involves myeloid-derived suppressor cells (MDSCs), immature myeloid cells. They are immunosuppressive, suppressing T-cell proliferation and activation. The role of MDSCs in sepsis is hotly debated. It is unclear whether activated MDSCs are beneficial in fighting sepsis through increasing innate immune responses to bacteria, or whether expansion of MDSCs leads to adaptive immune suppression followed by secondary infection. Lai et al. reviewed the role of MDSCs in sepsis [100], including the potential use of sildenafil to inhibit the signal pathways that regulate the production of the suppressive factors of MDSCs. Drawing from research on use of sildenafil to fight cancer cells by boosting the immune system, they noted that this PDE5 inhibitor reduced arginase- 1 and nitric oxide synthase- 2 expression in a mouse tumor model. It also enhanced intratumoral T-cell infiltration and activation, reduced tumor outgrowth, and improved the antitumor efficacy of adoptive T-cell therapy. Furthermore, sildenafil restored T-cell proliferation of peripheral blood mononuclear cells from multiple myeloma and head and neck cancer patients in vitro [101]. They suggested exploration of potential for similar properties of sildenafil in the context of sepsis.

A potential concern with use of sildenafil in sepsis is that its vasodilator action might lead to exacerbation of arterial hypotension. The drug has only a mild effect on blood pressure, so this may be a minor consideration compared with its protective effects on the microvasculature. Some information from humans is available. In a retrospective analysis of 17 neonates given sildenafil for 
treatment of pulmonary hypertension secondary to meconium aspiration syndrome (MAS) or sepsis, no significant decrease in blood pressure or increase in vasopressor/inotrope requirement occurred [102]. However, definitive studies are lacking, and it is currently unknown whether administration of sildenafil to patients with sepsis is efficacious and safe.

\subsubsection{Cannabidiol (CBD)}

The arachidonic acid derivatives 2-arachidonoyl glycerol and anandamide are endocannabinoids produced excessively in sepsis and they are potential factors leading to immune dysfunction and inflammation [103]. Inflammation is the necessary response of the infected host, controlled by neutrophil recruitment to the site of inflammation [104], however, too much inflammation or unresolved inflammation can lead to many acute and chronic diseases including sepsis [105].

Inflammation and inflammatory disorders, including sepsis, could be modulated by endogenous chemical signalling molecules and their receptors. Among these, endocannabinoids are released in response to inflammatory stimuli and their levels are elevated in patients and animals with septic shock [106]. Three receptors of endocannabinoids have received attention as potential ways to treat sepsis, the CB2 receptor, the transient receptor potential vanilloid subfamily, member 1 (TRPV1), and the GPR55 receptor (The latter has sometimes been referred to as the CB3 receptor). Endocannabinoids suppress immune cell function by binding to G-proteincoupled CB2 receptors on immune cells $[107,108]$. In vitro, CB2R activation has been shown to inhibit leukocyte proliferation and migration, and promote immune cell apoptosis [109]. Activation of CB2R reduces activation of leukocytes and their interactions with blood vessel walls in septic mice. Also, CB2R activation reduces leukocyte-endothelial interactions and the proinflammatory cytokines, TNF, IL-1 $\beta$ and IL- 6 in plasma of septic mice [110112].

CB2R may be an attractive target for modulating the inflammatory response in sepsis.

While the distribution of CB2 receptors is primarily in immune cells, the distribution of GPR55 is extensive throughout the body. Current evidence indicates GPR55 involvement in the gut during septic ileus [113] and in both inflammatory and neuropathic pain [114-117]. In animal models, several groups have investigated the effect of either knock-out of cannabinoid receptors or their modulation by drug-like molecules. Yang used LPS challenge in mice to investigate the therapeutic potential of CB2R and GPR55 modulation [118]. The author concluded that CB2R activation and GPR55 inhibition may 
significantly attenuate the hyper-inflammatory response of sepsis and therefore possibly improve patient outcomes, and even reduce mortality.

Others have used different animal models, particularly the cecal ligation and puncture model and also knock-out models in which the CB2 receptor has been deleted. Csoka etal. found that CB2 receptor inactivation by knockout decreased sepsis-induced mortality, and bacterial translocation into the bloodstream of septic animals [119]. Furthermore, CB2 receptor inactivation decreased kidney and muscle injury, suppressed splenic NF-kB activation, and diminished the production of IL-10, IL- 6 and MIP-2. CB2 receptor deficiency prevented apoptosis in lymphoid organs and augmented the number of $\mathrm{CD}_{11 \mathrm{~b}^{+}}$and CD19+ cells during CLP.

However, Tschöp et al. reported the opposite findings [120]. This group also used a cecal ligation and puncture (CLP) model of sepsis, and found that CB2Rknock out mice showed decreased survival as compared with wild-type mice. CB2R-KO mice also had increased serum IL-6 and bacteremia. Twenty-four hours after CLP, the CB2R-deficient mice had increased lung injury, increased neutrophil recruitment, decreased neutrophil activation. CB2R-agonist treatment in wild-type mice increased the mean survival time and decreased neutrophil recruitment, decreased serum IL-6 levels, bacteremia, and damage to the lungs. Gui et al. also proposed that CB2 receptor has a protective action in sepsis [121], and Lehman et al. proposed that CB2 activation reduces intestinal leukocyte recruitment and systemic inflammatory mediator release in acute experimental sepsis [122].

These opposing results leave open the specific contribution of CB2R to sepsis. Kasten etal. provided a possible explanation by suggesting that CB2R mediation of inflammation is dependent upon the severity of sepsis [123]. They suggested that in more severe models of sepsis, the inflammatory response drives hemodynamic changes that result in cardiopulmonary arrest and death. However, in less severe CLP models, inefficient clearance of bacterial pathogens leads to prolongation of the infectious process and resultant death. Thus, "attenuation of inflammation would prove more beneficial in a severe model of CLP, while being harmful in a moderate model of CLP."

Several papers have reported the effect of the phytocannabinoid drug cannabidiol (CBD) in models of sepsis. CBD is a nonpsychoactive component of marijuana. More than 80 clinical trials have investigated the effects of CBD in various diseases from inflammatory bowel disease to graft versus host disease. It was found to be safe in humans. Chronic administration of CBD for 30 days to healthy volunteers, at daily doses ranging from $10-400 \mathrm{mg}$, failed to induce any significant alteration in neurological, psychiatric or clinical exams $[124,125]$. CBD-based formulations are approved for the management of multiple sclerosis in at least 27 countries, and CBD also received U.S. Food and Drug Administration approval for the treatment of refractory childhood 
epilepsy and glioblastoma multiforme tumours. CBD appears to act at several receptors including CB2R and GPR55.

In the cecal ligation model in vivo, cannabidiol has shown protective action in several laboratories. In 2010, Cassol et al. provided the first study in the rat CLP model [126]. Rats were treated with CBD (at 2.5, 5, or $10 \mathrm{mg} \mathrm{kg}^{-1}$ once or daily for 9 days after CLP) or vehicle. CBD ameliorated cognitive impairment, and significantly reduced mortality in rats submitted to CLP.

In 2011 Ruiz-Valdepeñas et al. reported using LPS challenge in place of the CLP model [127]. They showed that CBD reduces LPS-induced vascular changes and inflammation in the mouse brain. CBD prevented LPS-induced arteriolar and venular vasodilation as well as leukocyte margination. It abolished LPSinduced increases in TNF-alpha and preserved blood brain barrier integrity.

In 2012, based on a bacterial meningitis model in Wistar rats, Barichello et al. reported that cannabidiol administered by intraperitoneal injection reduced host immune response (TNF- $\alpha$ ) and prevented cognitive impairment [128]. Then in 2014 Ribeiro et al. showed that CBD improves lung function and inflammation in mice submitted to LPS-induced acute lung injury [129]. CBD decreased total lung resistance and elastance, leukocyte migration into the lungs, myeloperoxidase activity in the lung tissue, protein concentration and production of pro-inflammatory cytokines (TNF and IL-6) and chemokines (MCP-1 and MIP-2) in the bronchoalveolar lavage supernatant.

In addition, very recent publications show CBD has beneficial effects on mitochondrial function [130]. It reverses the reduction in mitochondrial capacity induced by poor supply of oxygen and glucose. In the heart, CBD modulates mitochondrial function and biogenesis to protect the heart against doxorubicin-induced cardiomyopathy during cancer treatment [131]. It also protects the heart in studies in mice from auto-immune $\mathrm{CD}^{3+}$ and $\mathrm{CD}^{4+} \mathrm{T}$ cellmediated inflammatory response and injury, myocardial fibrosis and cardiac dysfunction [132]. Similar positive effects on mitochondrial function have been demonstrated in the rat brain [133]. CBD also exerts neuroprotective effects against mitochondrial toxins, and restores intracellular $\mathrm{Ca}^{2+}$ homeostasis in human neuroblastoma cell lines [134]. These data suggest that CBD is a mitochondria-targeting drug that protects and enhances mitochondrial function and bioenergetics, effects that might be relevant in treatment of sepsis.

CBD also has some moderate antibacterial action against Gram-positive bacteria. The bactericidal concentrations of CBD for staphylococci and streptococci in broth are in the range of $1-5 \mu \mathrm{g} \mathrm{ml}^{-1}$, with activity dropping more than 10 -fold in the presence of $4 \%$ serum or $5 \%$ blood. Gram-negative bacteria are resistant to CBD [135].

In summary, endocannabinoids are produced excessively in sepsis and they are potential factors leading to immune dysfunction and inflammation. The 
endocannabinoid modulator cannabidiol has shown promising results in laboratory studies and may be a candidate for treatment for sepsis and septic shock. Studies in humans are required to test this possibility.

\subsubsection{Immune regulation by (some) antibiotics}

Some (not all) antibiotics have additional pharmacological properties in addition to their ability to directly kill bacteria. They can interact with host immune cells and regulate immune function, with potential for beneficial effects in various inflammatory conditions including sepsis. Tetracyclines such as doxycycline and minocycline, and macrolides such as erythromycin, have anti-inflammatory properties due to their ability to regulate the expression of inflammatory cytokines and TLRs in response to LPS [136]. Doxycyclin inhibits LPS-induced NO production by immune cells in vitro [137] and reduces IL-1 $\beta$ and IL-6 expression. Tetracyclines such as doxycycline also possess strong metal chelating properties [138] inhibiting protein kinase C [139]. PKC inhibitors are known to reduce LPS-stimulated cytokine secretion [140,141] therefore the chelating properties of doxycycline might also reduce the IL- $1 \beta$ and IL-6 expression through PKC inhibition. Macrolides such as erythromycin appear to modulate immune function by a different mechanism, by blocking activation of transcription factors NF- $\mathrm{KB}$ and IRF3 [142] with concomitant reduction of both pro-and anti-inflammatory cytokines.

There is extensive evidence for reduction in clinical death rates with macrolide antibiotics beyond that expected from their antibiotic action alone. This has been reviewed by Amsden [143]. For severe lung infections, macrolides are associated with decreased length of hospitalisation and mortality when used alone or in combination with beta-lactam antibiotics [144]. The macrolide azithromycin may modulate inflammation by enhancement of host defence mechanisms shortly after initial administration followed by curtailment of local infection and inflammation in the following period [145].

In the years since publication of the review by Amsden, additional evidence has accumulated for the protective effects of macrolides. A meta-analysis published in 2014 by Sligl et al. found significantly better outcomes with macrolide therapy for critically ill patients with community-acquired pneumonia [146]. In observational studies of almost 10,000 critically ill patients with community-acquired pneumonia, macrolide use was associated with a significant $18 \%$ relative $(3 \%$ absolute) reduction in mortality compared with non-macrolide therapies. An even larger mortality reduction was observed after pooling data from studies that provided adjusted risk estimates. The authors concluded that "These results suggest that macrolides be considered first-line combination treatment in critically ill patients with community-acquired pneumonia." 
Similar positive data was reported from a study of use of combinations of antibiotics that included a macrolide in severely ill patients in ICUs. MartinLoeches et al. conducted a study of intubated patients admitted to the ICU with severe community-acquired pneumonia [147]. This was a prospective, observational, multicenter study conducted in 27 ICUs of 9 European countries. Two hundred eighteen consecutive patients requiring invasive mechanical ventilation for an admission diagnosis of CAP were recruited. Severe sepsis and septic shock were present in $165(75.7 \%)$ patients. ICU mortality was $37.6 \%$. Monotherapy was given in $43(19.7 \%)$ and combination therapy in 175 (80.3\%) patients. Macrolide use was associated with lower ICU mortality (hazard ratio, HR 0.48, confidence intervals, $95 \%$ CI $0.23-0.97$, $\mathrm{P}=0.04$ ) when compared to the use of fluoroquinolones. When more severe patients presenting severe sepsis and septic shock were analyzed $(n=92)$, similar results were obtained (HR 0.44, $95 \%$ CI $0.20-0.95, \mathrm{P}=0.03$ ). The authors concluded that "Combination therapy with macrolides should be preferred in intubated patients with severe CAP."

At least part of the additional effect of macrolides has been shown to be via reduction of inflammatory cytokines [148-151]. Macrolides contain two sugars and their spacing resembles those of the sugars in LPS and also those in the experimental drug PETIM-DG invented by Sunil Shaunak, which blocks interaction of bacterial LPS with TLR4/MD2, giving good protection in a rabbit model of bacterial dysentery [152]. This appears to be a powerful therapeutic mechanism: a study of oral PETIM-DG with no concurrent antibiotic in nonhuman primates infected with highly lethal Shigella dysenteriae type 1 bacteria gave a high level of protection and reduced death rate [153]. Note that this reduction in death rates was achieved without use of antibiotics. Though PETIM-DG is currently not a marketed drug, this study does highlight the potential for use of alternatives to antibiotics in treatment of serious infections. It remains to be proven whether macrolides modulate the innate immune inflammatory response similarly to PETIM-DG by antagonism of TLR4/MD2.

Macrolide antibiotics have also been shown to inhibit the quorum sensing (QS) ability of bacteria. This action occurs at lower concentrations than their antibacterial activity [154-156]. For example, erythromycin suppresses QS signals of $P$. aeruginosa including hemagglutinins, protease, hemolysin and AHL signals [157]. Azithromycin also affects QS-regulated virulence genes both in vitro [155-156] and in vivo [158]. It has been suggested than these actions might exploited to enhance antibiotic therapy by targeting bacterial behaviour [159].

The use of antibiotic combinations for joint effects on QS and cell kill remains a relatively little explored opportunity.

Tetracycline antibiotics also have non-antibiotic properties that might be exploited in severely ill patients. Evidence is available showing protective effects in the brain, particularly by modulation of the inflammatory actions of 
microglia, which fulfil an innate immune role in brain similar to that of macrophages in the periphery. Microglia mediate inflammation in various infectious and neurodegenerative diseases. The ability of minocycline to inhibit microglia has been studied for example in LPS damage to retina [160], global cerebral ischemia [161], focal cerebral ischemia [162-164], and traumatic brain injury $[165,166]$. Studies of the effect of minocycline in animal models of sepsis have shown that it decreases brain inflammation induced by systemic and brain administration of LPS $[167,168]$. In a rat CLP sepsis model, minocycline prevented an increase in markers of oxidative damage and inflammation in the hippocampus after sepsis. This was associated with improved long-term cognitive performance in sepsis survivors [169]. Blockade of microglia activation by minocycline was able to decrease not only hippocampus cytokine levels but also the disruption of the BBB, perhaps because minocycline decreases the activation of brain metalloproteinases. MMP activation is a pivotal step in disruption of the BBB $[170,171]$.

In summary, macrolide and tetracycline antibiotics have significant additional properties beyond killing bacteria. Their effects in vivo on inflammation, quorum sensing and protection of organs including the blood brain barrier suggests opportunity for 'repurposing' in combinations with other classes of antibiotic to extend opportunities for overcoming antibiotic resistance.

\subsection{CALL TO ACTION}

This paper has summarised several opportunities to exploit drugs that are currently available to help reduce death rates from antibiotic resistance. These opportunities do not depend on the difficult, slow and costly task of inventing new antibiotics, and they could be tested and implemented very rapidly to fill the (probably large) gap in time before new chemical and mechanistic classes of antibiotics become available. The overall theme is that repurposed drugs used in combinations could be explored more rigorously to reduce resistance and preserve antibiotic efficacy, and to protect organs from damage leading to disability and death. The key facts and actions required are summarised here:

i) The idea of using combinations of (non-antibiotic) beta-lactamase inhibitors as resistance-breakers appears to be unexploited. Several combinations of beta-lactam antibiotic plus lactamase inhibitor are commercially available and these number among our most valuable antibiotics, yet there are no available combinations of a beta-lactam antibiotic with two or more non-antibiotic lactamase inhibitors. Also, the possibility of combining two antibiotics with a lactamase inhibitor appears to be totally unexplored. If proven effective, these ideas alone could transform treatment options against our most serious bacterial infections. 
ii) The fact that only a single combination of two antibiotics has been approved for treating Gram-negative bacteria is shocking. (Cotrimoxazole is the only combination registered by the FDA and EMA that treats Gram-negative bacteria). Combinations of drugs have been thoroughly explored and registered for use to improve efficacy and overcome resistance for infectious diseases such as tuberculosis, HIV, and hepatitis $\mathrm{C}$, but not against systemic infections by Gram-negative and Gram-positive bacteria. There are large numbers of available antibiotics that could be explored in combinations of two or three for synergistic effects and ability to overcome bacterial resistance.

iii) The additional non-antibiotic properties of macrolides and tetracyclines offer opportunity to use these drugs in combinations to reduce death rates in clinical practice. These properties should be kept in mind when selecting combinations of antibiotics as suggested above. Simple bacterial kill assays will not help detect these effects. Relevant assays both in vitro and in vivo need to be used more routinely in the antibacterial field. Over-reliance on simple in vitro bacterial kill assays may be limiting the discovery of break-through treatments. If these antibiotics could be shown useful in vivo when used in combinations with other antibiotics against some of the most serious resistant bacteria, it could allow lower use of beta-lactam antibiotics and possibly side-step the concern about CREs.

iv) The lethality of bacteria derives from the damage to organs of the body. Strategies to protect organs during infection remain little explored. Particularly, reduction in deaths from sepsis and septic shock may depend on non-antibiotic interventions designed to protect kidneys, heart, lung, brain and other organs. Several options have been summarised in this review. Additional scientific publications not covered here suggest that other organ-protecting drugs and nutraceuticals might be available for repurposing: these require additional investigation. Use of these repurposed drugs alongside antibiotics could reduce death rates. Recovery from sepsis could be faster, allowing reduction in use of antibiotics. This could help slow development of antibiotic resistance globally and make our precious antibiotics last longer.

v) Moreover, current guidelines for treatment of sepsis and other indications do not account for the impact of antibiotics (positive and negative) on the peripheral and central immune systems, despite widespread immune dysregulation in sepsis. The potential positive effects of macrolides and tetracyclines have been summarised above. This article has highlighted the positive effects of some antibiotics on the immune system, but it is also possible that some antibiotics have unrecognised negative effects on for instance immune-regulated inflammation, quorum sensing, organ protection or gut microbiome 
which could work against curing the patient. Further study of these immune modulatory effects of antibiotics could lead to change in treatment of sepsis and other conditions. Again, this emphasises that simple bacterial-kill assays need supplementing with moresophisticated in vitro and in vivo assays that give a realistic view of the impact in humans of antibiotics and other treatments.

vi) Strategies to side-step the emerging crisis of CRE's and other bacteria with ESBLs and MBLs should be explored by use of combinations of antibiotics excluding beta-lactams. If host-mediated mechanisms can be exploited to boost host defence and protect organs, this could include replacement of bactericidal antibiotics such as beta-lactams, aminoglycosides, and fluoroquinolones with bacteriostatic antibiotics such as macrolides, tetracyclines and sulphonamides. A meta-analysis showed no reduction in cure rates against abdominal, lung and soft tissue infections when bacteriostatics were compared with bactericidals [16].

Antibiotics in use today were discovered using $20^{\text {th }}$ century technologies. The past decade has delivered many significant advances in technology that could help with maximising benefit from currently available drugs, such as the internet, smart-phones, Electronic Health Records, genomics/ metabolomics/ transcriptomics, big data and machine learning. Initiatives such as CMAP at the Broad Institute, which established the first collection of genome-wide transcriptional expression data from drug-treated human cells, are beginning to guide drug repurposing efforts [172]. Internet-based connectivity allows discovery of unexpected connections in health data, leading to rapid implementation of new treatment regimes, as beautifully illustrated in a TEDmed talk [173]. Also, the internet is now offering global research platforms to foster collaborative research, illustrated by Worldlabs and the global S.E.P.S.I.S. community [174].

In closing, there is real reason for concern about antibiotic resistance, but invention of new antibiotics is not the only solution. Repurposing opportunities for antibiotics and non-antibiotics described in this article (together with additional ideas summarised in an earlier review by this author [175]) may be able to fill the gap before new antibiotics classes are discovered.

\section{AUTHOR DECLARATION OF INTERESTS}

I was named co-inventor on the patent for sildenafil / Viagra. I have no commercial or monetary interest in the drug. I have no monetary interest in any of the other drugs mentioned in this article. 


\section{REFERENCES}

1. A.R.M. Coates, G. Halls, Y. Hu, Br. J. Pharm. 163 (2011) 184-194.

2. $\quad$ M.P. Fink, H. S. Warren, Nat. Rev. Drug Discovery 13 (2014) 741-758.

3. $\quad$ L.B. Rice, J. Infect. Dis. 197 (2008) 1079-1081.

4. N. Woodford, D.W. Wareham, B. Guerra, C. Teale, J. Antimicrob. Chemother. 69 (2014) 287-291.

5. https://amr-review.org/sites/default/files/AMR\%20Review\%20Paper\%20\%20Tackling $\% 20 \mathrm{a} \% 20$ crisis $\% 20$ for $\% 20$ the $\% 20$ health $\% 20$ and $\% 20$ wealth $\%$ 20of\%20nations 1.pdf

6. V.L. Simpkin, M.J. Renwick, R. Kelly, E. Mossialos, J. Antibiotics advance online publication (2017) doi:10.1038/ja.2017.124

7. www.pewtrusts.org/en/research-and-analysis/issuebriefs/2014/03/12/tracking-the-pipeline-of-antibiotics-in-development

8. R.P Bax, R. Anderson, J. Crew, P. Fletcher, T. Johnson, E. Kaplan, Nat. Med. 4 (1998) 545-546.

9. N. Woodford, D. W. Wareham, B. Guerra. C. Teale, J Antimicrob Chemother 69 (2014) 287-291.

10. http://www.helperby.com/pipeline

11. D. J. Mason, I. Stott, S. Ashenden, Z. B. Weinstein, I. Karakoc, S. Meral, N. Kuru, A. Bender, M. Cokol, J. Med. Chem. 60 (2017) 3902-3912.

12. A. Zimmer, I. Katzir, E. Dekel, A.E. Mayo, U. Alon, Proc. Natl. Acad. Sci. U.S.A. 113 (2016) 10442-10447.

13. K. Wood, S. Nishida, E.D. Sontag, P. Cluzel, Proc. Natl. Acad. Sci. U.S.A. 109 (2012) 12254-12259.

14. M. Cokol, N. Kuru, E. Bicak, J. Larkins-Ford, B.B. Aldridge, Sci. Adv. 3 (2017) e1701881.

15. K.B. Wood, Proc. Natl. Acad. Sci. U.S.A. 113 (2016) 10231-10233.

16. J. Nemeth, G. Oesch, S.P. Kuster, J. Antimicrob. Chemother. 70 (2015) 382-395.

17. P.E. Marik, V. Khangoora, R. Rivera, M.H. Hooper, J. Catravas, Chest (2017) 151 1229-1238.

18. T.J. Iwashyna, E.W. Ely, D.M. Smith, K.M, Langa, JAMA 304 (2010) 1787-1794.

19. D.C. Angus, J. Carlet, Intens. Care Med. 29 (2003) 368-77.

20. R.P. Dellinger, M.M. Levy, A. Rhodes, et al., Crit. Care Med. 39 (2013) 165-228.

21. D.C. Angus, W.T. Linde-Zwirble, J. Lidicker, G. Clermont, J. Carcillo, M.R. Pinsky, Crit. Care Med. 29 (2001) 1303-1310

22. T. Lagu, M.B. Rothberg, M.S. Shieh, P.S. Pekow, J.S. Steingrub, P.K. Lindenauer. Crit. Care Med. 40 (2012) 754-6 Erratum, Crit. Care Med. 40 (2012) 2932.

23. J.L. Vincent, J. Rello, J. Marshall, JAMA 302 (2009) 2323-2329.

24. D.C. Angus, T. van der Poll, N. Engl. J. Med. 369 (2013) 840-51.

25. R.V. D'Elia, K. Harrison, P.C. Oyston, R.A. Lukaszewski, G.C. Clark, Clin. Vacc. Immunol. 20 (2013) 319-327.

26. J. Teng, A. Pourmanda, M. Mazer-Amirshahi, J. Crit. Care. 43 (2018) 230-234.

27. T. Sharshar, R. Carlier, A. Blanchard, et al., Crit. Care Med. 30 (2002) 497-500.

28. A.A Fowler, A.A. Syed, S. Knowlson, et al., J. Transl. Med. 12 (2014) 32.

29. C. Hunt, N.K. Chakravorty, G. Annan, N. Habibzadeh, C.J. Schorah, Int. J. Vitam. Nutr. Res. 64 (1994) 212-219.

30. C.J. Schorah C. Downing, A. Piripitsi. L. Gallivan, A.H. Al-Hazaa, M.J. Sanderson et al., Am. J. Clin. Nutr. 63 (1996) 760-765. 
31. E. Borrelli, P. Roux-Lombard, G.E. Grau, E, Girardin, B. Ricou, J.M. Dayer. P.M, Suter, Crit. Care Med. 24 (1996) 392-397.

32. H.F. Galley, M.J. Davies, N.R. Webster, Free Rad. Biol. Med. 20 (1996) 139-143.

33. A.C. Carr, G.M. Shaw, A.A. Fowler, et al., Crit. Care 19 (2015) 418-425.

34. J.S. Zipursky, A. Alhashemi, D. Juurlink, BMJ Case Rep. Published online: doi: 10.1136/bcr-2013-201982.

35. P.F. Dillon, R.S. Root-Bernstein, C.M. Lieder, Am. J. Physiol. Heart Circ. Physiol. 286 (2004) H2353-2360.

36. R.P. Dellinger, M. Levy, A.A. Rhodes, et al., Intensive Care Med. 39 (2013) 165228.

37. W.A. Koekkoek, A.R. van Zanten, Nutr. Clin Pract. 31 (2016) 457-474.

38. J.X. Wilson, Antioxidants \& Redox Signaling. 19 (2013) 2129-2140.

39. M.M. Berger, H.M. Oudemans-van Straaten, Curr. Opin. Clin. Nutr. Metab. Care 18 (2015) 193-201.

40. S.J. Mo, E.W Son, D.K. Rhee, et al., Arch. Pharm. Res. 26 (2003) 244-251.

41. J. Haendeler, A.M. Zeiher, S. Dimmeler, Eur. J. Pharmacol. 317 (1996) 407-411.

42. C. Fiorito, M. Rienzo, E. Crimi, et al., Free Radic. Res. 42 (2008) 754-762.

43. P.E. Marik, Crit. Care Med. 44 (2016) 1228-1229.

44. J. Armour. K. Tyml, D. Lidington, et al., J. Appl. Physiol. 90 (2001) 795-803.

45. F. Wu, J.X. Wilson, K. Tyml, Am. J. Physiol. Regul. Integr. Comp. Physiol. 285 (2003) R50-R56,

46. F. Wu, J.X. Wilson, K. Tyml, Free Radic. Biol. Med. 37 (2004) 1282-1289.

47. F. Wu, D.P. Schuster, K. Tyml, J.X. Wilson, Free Radic. Biol. Med. 42 (2007) 124131.

48. F. Wu, J.X. Wilson, Cardiovasc. Res. 81 (2009) 38-45.

49. J.P. Gaut, J. Byunc. J. Roberts, et al., Free Rad. Biol. Med. 40 (2006) 1494-1501.

50. B.J. Fisher, I.M Seropian, D. Kraskauskas, Crit. Care Med. 39 (2011) 1454-60.

51. G. Zhou, G. Kamenos, S. Pendem, J. X. Wilson, F. Wu, Am. J. Physiol. Regul. Integr. Comp. Physiol. 302 (2012) R409-R416.

52. B. J. Fisher, D. Kraskauskas, E. J. Martin, et al., J. Parenteral Enteral Nutrition. 38 (2014) 825-839.

53. J.X. Wilson, Biofactors 35 (2009) 5-13.

54. M. Han, S. Pendem, S.L. Teh, et al., Free Radic. Biol. Med. 48 (2010) 128-135.

55. A.B. Nathens, M.J. Neff, G.J. Jurkovich, et al., Annal Surg. 236 (2002) 814-822.

56. E. Crimi, A. Liguori, M. Condorelli, et al., Anesth. Analg. 99 (2004) 857-863.

57. J.X. Wilson, Antioxid. Redox Signal. 19 (2013) 2129-2140.

58. A.C. Carr, G.M. Shaw, A.A. Fowler, R. Natarajan, Critical Care 19 (2015) 418.

59. A.A Fowler, A.A Syed, S. Knowlson, J. Transl. Med. 12 (2014) 32-41.

60. M.H. Zabet, M. Mohammadi. Ramezani, H. Khalili, J. Res. Pharm. Pract. 5 (2016) 94-100.

61. P.E. Marik, V. Khangoora, R. Rivera, M.H. Hooper, J. Catravas, Chest 151 (2017) 1229-1238.

62. W. Manzanares, G. Hardy, Curr. Opin. Clin. Nutr. \& Metab. Care 14 (2011) 610617.

63. https://emcrit.org/pulmcrit/metabolic-sepsis-resuscitation/

64. J. Teng, A. Pourmanda, M. Mazer-Amirshahi, J. Crit. Care 43 (2018) 230-234.

65. J. Aman, M.J.L. Peters, C. Weenink, G.P. Van Nieuw Amerongen, A.V. Noordegraaf, Amer. J. Resp. Critical Care Med. 188 (2013) 1171-1173. 
66. A.N. Rizzo, J. Aman, G.P. Van Nieuw Amerongen, S.M. Dudek, Arterioscl. Thromb. Vasc. Biol. 35 (2015) 1071-1079.

67. J. Aman, J. van Bezu, A. Damanafshan, et al., Circulation 126 (2012) 27282738.

68. R.S. Stephens, L. Johnston, L. Servinsky, B.S. Kim, M. Damarla, Physiol. Rep. 3 (2015) doi: 10.14814/phy2.12589.

69. A.N. Rizzo, S. Sammani, A.E. Esquinca, J.R. Jacobson, J.G.N. Garcia, E. Letsiou, S.M. Dudek, Am. J. Physiol. Lung Cell. Mol. Physiol. doi: 10.1152/ajplung.00031.2015.

70. M.Z. Adzemovic, M. Zeitelhofer, U. Eriksson, et al., (2013). PLoS ONE 8 e56586. doi: 10.1371/journal.pone.0056586.

71. M.S. Penn, M. Kamath, Circulation. 126 (2012) 2677-2679.

72. P.J. Woodring, T. Hunter, J.Y. J. Wang, J. Cell Sci. 116 (2003) 2613-2626.

73. E. Cadirci, Z. Halici, F. Odabasoglu, et al., Clin. Exp. Immunol. 166 (2011) 374384.

74. M.D.F. Carvalho, I.T. Silvestre, A.J.G. Risuenho, et al., J. Surg. Clin. Res. 2 (2011) 78-86.

75. M. Deng, P. Loughran, L. Zhang, M. Scott, T. Billiar, Sci. Signaling 8 (2015) doi: 10.1126/scisignal.2005548.

76. M. Knotek, B. Rogachev, W. Wang, T. Ecder, V. Melnikov, P. Gengaro, M. Esson, C. Edelstein, C. Dinarello, R. Schrier, Kidney internat. 59 (2001) 2243-2249.

77. I. Garcia, Y. Miyazaki, K. Araki, M. Araki, R. Lucas, G. Grau, G. Milon, Y. Belkaid, C. Montixi, W. Lesslauer, P. Vassalli, Eur. J. Immunol. 25 (1995) 2401-2407.

78. R. Chanthaphavong, P. Loughran, T. Lee, M. Scott, T. Billiar, J. Biol. Chem. 287 (2012) 35887-35898.

79. V. Kovalski, A.P. Prestes J.G. Oliveira, et al., Eur. J. Pharmacol. 807 (2017) 174181.

80. E. Benli, S.N. Ayyildiz, S. Cirrik, et al., Int. Braz. J. Urol. 43 (2017) 345-355.

81. R. Ockaili, F. Salloum, J. Hawkins, R.C. Kukreja, Am. J. Physiol. Heart Circ. Physiol. 283 (2002) H1263-H1269.

82. M.A.S. Fernandes, R.J.F Marques, J.A.F. Vicente, et al., Mol. Cell Biochem. 309 (2008) 77.

83. R.M. Whitaker, L.P. Wills, L. J. Stallons, R.G. Schnellmann, J. Pharmacol. Exp. Ther. 347 (2013) 626-634.

84. F. Salloum, L. Xi, R. Ockaili, C. Yin, R. C, Kukreja, Circulation 106 (2002) 1880 [Suppl. S II-378 (Abstract)].

85. A. Das, R. Ockaili, F. Salloum, R.C Kukreja, Am. J. Physiol: Heart Circ. Physiol. 286 (2003) 1455-1460.

86. F. Salloum, C. Yin, L. Xi, R.C. Kukreja, Circ. Res. 92 (2003) 595-597.

87. R.C. Kukreja, R. Ockaili, F. Salloum, et al., J. Mol. Cell. Cardiol. 36 (2004) 165173.

88. R.C. Kukreja, F. Salloum, A. Das, et al., Vascul. Pharmacol. 42 (2005) 219-232.

89. A. Das, L. Xi, R.C. Kukreja, J. Biol. Chem. 280 (2005) 12944-12955.

90. R.C. Kukreja, Cardiovasc. Drugs Ther. 20 (2006) 5-8.

91. R.C. Kukreja, Br. J. Pharmacol. 150 (2007) 538-540.

92. F.N. Salloum, A. Das, C.S. Thomas, C. Yin, R.C. Kukreja, J. Molec. Cell. Cardiol. 43 (2007) 545-551.

93. V.Q. Chau, F.N. Salloum, N.N. Hoke, A. Abbate, R.C. Kukreja, Am. J. Physiol. Heart Circ. Physiol. 300 (2011) H2272-H2279. 
94. M.M. Redfield, H.H. Chen, B.A Borlaug, et al., JAMA. 309 (2013) 1268-1277.

95. A. Yildirim, Y. Ersoy, F. Ercan, et al., Pulmon. Pharmacol. Therapeut. 23 (2010) 215-221,

96. D.A. Kemper, D.R. Otsuki, N. Maia, et al., Intens. Care Med. Experimenta 2 (2014) 53.

97. A.T. Bender J. A. Beavo, Neurochem. Internat. 45 (2004) 853-857.

98. S. Zhao, L. Zhang, G. Lian, et al., Internal. Immunopharmacol. 11 (2011) 468474.

99. M. Kniotek, A. Boguska, J. Immunol. Res. (2017), Article ID 4541958.

100. G. Lai, C. Qin, Q. Shu, BioMed. Res. Internat. (2014), Article ID 598654.

101. P. Sera, K. Meckel, M. Kelso, et al., J. Med. 203 (2006) 2691-2702,

102. J. Limjoco, L. Paquette, R. Ramanathan, I. Seri, P. Friedlich, Am. J. Therapeut. 22 (2015) 125-131.

103. T.W. Klein, Nat. Rev. Immunol 5 (2005) 400-411.

104. A. Ryan, C. Godson, Curr. Opin. Pharmacol. 10 (2010) 166-172.

105. L.V. Norling, C.N. Serhan, J. Intern. Med. 268 (2010) 15-24.

106. C. Lehmann, M. Kianan, J. Zhou, V. Cerny, M Kelly, Signa Vitae 6 (2011) 7-13.

107. R.G. Pertwee, Handbook Exp. Pharmacol. 231 (2015) 1-37.

108. B. Cs'oka, Z. H. N'emeth, P. Mukhopadhyay et al., PLoS ONE 4 Article ID e6409, (2009).

109. S. Basu, B. Dittel, Immunol. Res. 51 (2011) 26-38.

110. C. Lehmann, M. Kianian, J. Zhou, et al., Crit. Care. 16, R47. doi: $10.1186 /$ cc11248.

111. J. Sardinha, M. Kelly, J. Zhou, C. Lehmann., Mediators Inflamm. (2014) 978678.

112. J.T. Toguri, C. Lehmann, R.B. Laprairie, et al., Br. J. Pharmacol. 171 (2014) 1448-1461.

113. Y.-Y. Li, Y.-N. Li, J.-B. Ni, et al., Neurogastroenterol. Motil. 22 (2010) 350.

114. P.C. Staton, J.P. Hatcher, D.J. Walker, et al., Pain 139 (2008) 225-236.

115. N.A. Balenga, E. Aflaki, J. Kargl, et al., Cell Res. 21 (2011) 1452-1469.

116. G. Cantarella, M. Scollo, L. Lempereur, Biochem. Pharmacol. 82 380-388.

117. V. Chiurchiù, M. Lanuti, M. Bardi, et al., Int. Immunol. 27 (2014) 153-160.

118. Thesis: Cannabinoid 2 receptor and GPR55 as therapeutic targets in experimental sepsis. O.H. Yang (2017) dalspace.library.dal.ca

119. B. Cso' ka, Z.H. Ne'meth, P. Mukhopadhyay, et al., PLoS ONE 4 (2009) e6409. doi: 10.1371/journal.pone.0006409.

120. J. Tschöp, K.R. Kasten, R. Nogueiras, et al., J. Immunol. 183 (2009) 499-505.

121. H. Gui, Y. Sun, Z.-M. Luo, D.-F. Su, S.-M. Dai, X. Liu, Mediat. Inflamm. (2013) https://doi.org/10.1155/2013/741303 Article ID 741303.

122. C. Lehmann, M. Kianian, J. Zhou, et al., Crit. Care 16 (2012) R47.

123. K.R. Kasten, J. Tschöp, M.H. Tschöp, C.C. Caldwell, Endocrine Metabolic Immune Disorders - Drug Targets 10 (2010) 224-234.

124. A.W. Zuardi, J.A. Crippa, J.E. Hallak, et al., Braz. J. Med. Biol. Res. 39 (2006) 421429.

125. S. Zhornitsky, S, Potvin, Pharmaceuticals (Basel) 5 (2012) 529-552.

126. O.J. Cassol, C.M. Comim, B.R. Silva, et al., Brain Research 1348 (2010) 128-138.

127. L. Ruiz-Valdepeñas, J.A. Martínez-Orgado, C. Benito, et al., J. Neuroinflamm. 8 (2011) 5.

128. T. Barichello, R.A. Ceretta, J.S. Generoso, et al., Eur. J. Pharmacol. 697 (2012) 158-164. 
129. A. Ribeiro, V. I. Almeida, C. Costola-de-Souza, et al., Immunopharmacol. Immunotoxicol. 37 (2014) 1.

130. S. Sun, F. Hu, J. Wu, S. Zhang, Redox Biology 11 (2017) 577-585.

131. E. Hao, P. Mukhopadhyay, Z. Cao, et al., Mol. Med. 21 (2015) 38-45.

132. W-S. Lee, K. Erdelyi, C. Matyus, et al., Mol. Med. 22 (2016) 136-146.

133. S.S. Valvassori, D.V. Bavaresco, G. Scaini, et al., Rev. Bras. Psiquiatr. 35 (2013) 380-386.

134. D. Ryan, A.J. Drysdale, C. Lafourcade, R.G. Pertwee, B. Platt, J. Neurosci. 29 (2009) 2053-2063.

135. B. van Klingeren, M. ten Ham. B. van Klingeren, M. ten Ham, Antonie van Leeuwenhoek 42 (1976) 9-12.

136. J. Cazalis, C. Bodet, G. Gagnon, D. Grenier, J. Periodont. 79 (2008) 1762-1768.

137. J. Hoyt J, Ballering, H. Numanami, J., Hayden, R. Robbins, J. Immunol. 176 (2006) 567-572.

138. D. Grenier, M.P, Huot, D. Mayrand, Antimicrob. Agents Chemother. 44 (2000) 763-766.

139. L.M. Golub, N.S. Ramamurthy, T.F. McNamara, et al., Crit. Rev. Oral Biol. Med. 2 (1991) 297-321.

140. G.F. Webster, S.M Toso, L. Hegemann, Arch. Dermatol. 130 (1994) 748-52.

141. D.J. Loegering, M.R. Lennartz, Enzyme Res. (2011) 537821. Article ID 537821.

142. M. Desaki, H. Okazaki, T. Sunazuka, S. Omura, K. Yamamoto, H. Takizawa, Antimicrob. Agents Chemother. 48 (2004)1581-1585.

143. G.W. Amsden, J. Antimicrob. Chemother. 55 (2005) 10-21.

144. S. Kudoh, A. Azuma, M. Yamamoto, et al., Amer. J. Resp. Crit. Care Med. 157 (1998) 1829-1832.

145. S. Kudoh, T. Uetake, T. Hagiwara, et al., Nihon Kyobu Shikkan Gakkai Zasshi 25 (1987) 632-642.

146. W.I. Sligl, L. Asadi, Leyla, D.T Eurich, et al., Crit. Care Med. 42 (2014) 420-432.

147. I. Martin-Loeches, T. Lisboa, A. Rodriguez, et al., Intensive Care Med. DOI 10.1007/s00134-009-1730-y

148. O.A. Khair, R.J. Davies, J.L. Devalia, Eur. Resp. J. 9 (1996) 1913-1922.

149. H. Watabe, M. Araake, S. Morikawa, Antimicr. Agents Chemother. 40 (1996) 1366-1370.

150. M.J. Schultz, P. Speelman, S. Zaat, et al., Antimicr. Agents Chemother. 42 (1998) 3605-3609.

151. K. Oishi, F. Sonoda, S. Kobayashi, et al., Inf. Immunity 62 (1994) 4145-4152.

152. I. Teo, S.M. Toms, B. Marteyn, et al., EMBO Mol. Med. 4 (2012) 866-881.

153. D. Islam, E. Lombardini, N. Ruamsap, et al., Immunol. 147 (2016) 178-189.

154. J.C. Pechere, Jpn. J. Antibiot. 54 (2001) (Suppl. C) 87-89.

155. K. Tateda, R. Comte, J.C. Pechere, et al., Antimicrob. Agents Chemother. 45 (2001) 1930-1933.

156. Y. Nalca, L. Jansch, F. Bredenbruch, R. Geffers, J. Buer, S. Haussler, Antimicrob. Agents Chemother. 50 (2006) 1680-1688.

157. D. Sofer, N. Gilboa-Garber, A. Belz, N.C. Garber, Chemotherapy 45 (1999) 335341.

158. N. Hoffmann, B. Lee, M. Hentzer, et al., Antimicrob. Agents Chemother. $\mathbf{5 1}$ (2007) 3677-3687.

159. G. B. Rogers, M. P Carroll, K. D. Bruce, Brit. J. Pharmacol. 165 (2012) 845-857.

160. A.L. Wang, A.C. Yu, L.T. Lau, et al., Neurochem. Int. 47 (2005) 152-158. 
161. J. Yrjänheikki, R. Keinänen, M. Pellikka, et al., Proc. Natl. Acad. Sci. 95 (1998) 15769-15774.

162. J. Yrjanheikki, T. Tikka, R. Keinanen, et al., Proc. Natl. Acad. Sci. 96 (1999) 13496-13500.

163. C.X. Wang, T. Yang, A. Schuaib, Brain Res. 963 (2003) 327-329.

164. L. Xu, S.C. Fagan, J.L Waller, et al., BMC Neurol. 26 (2004) 4-7.

165. R.O. Sanchez Mejia, V.O. Ona, M. Li, R.M. Friedlander, Neurosurgery 48 (2001) 1393-1401.

166. T. Schmitz, G. Krabbe, G. Weikert, T. Scheuer, F. Matheus, Experiment. Neurol. 254 (2014) 153-165.

167. S.Y. Yoon, D. Patel, P.M. Dougherty, Neuroscience 221 (2012) 214-224.

168. F. Zhu, L. Zhang, Y.Q. Ding, J. Zhao, Y. Zheng, Brain Behav. Immun. 38 (2014) 166-174.

169. M. Michels, A.S. Vieira, F. Vuolo, Brain Behav. Immun. 43 (2015) 54-59.

170. S.C. Fagan, L.E. Cronic, D.C. Hess, Transl. Stroke Res. 2 (2011) 202-208.

171. F. Dal-Pizzol, H.A. Rojas, E.M. dos Santos, et al., Mol. Neurobiol. 48 (2013) 6270 .

172. https://www.broadinstitute.org/connectivity-map-cmap.

173. http://www.tedmed.com/talks/show?id=529433.

174. Worldlabs. www.worldlabs.org.

175. D. Brown, Nature Rev. Drug Discov. 14 (2015) 821-832.

(C)2018 by the authors; licensee IAPC, Zagreb, Croatia. This chapter is an open-access publication distributed under the terms and conditions of the Creative Commons Attribution license (http://creativecommons.org/licenses/by/3.0/) (cc) E EY 